\title{
Recent Developments and Challenges on AC Microgrids Fault Detection and Protection Systems-A Review
}

\author{
Noor Hussain ${ }^{1,2}$, Mashood Nasir ${ }^{1}$ (D), Juan Carlos Vasquez ${ }^{1(D)}$ and Josep M. Guerrero ${ }^{1, *(D)}$ \\ 1 Center for Research on Microgrids (CROM), Department of Energy Technology, Aalborg University, \\ 9220 Aalborg, Denmark; nhu@et.aau.dk (N.H.); mnas@et.aau.dk (M.N.); juq@et.aau.dk (J.C.V.) \\ 2 Electrical Engineering Department, Balochistan University of Engineering and Technology Khuzdar, \\ Khuzdar 89100, Pakistan \\ * Correspondence: joz@et.aau.dk; Tel.: (+45)-2037-8262
}

Received: 24 March 2020; Accepted: 24 April 2020; Published: 1 May 2020

\begin{abstract}
The protection of AC microgrids (MGs) is an issue of paramount importance to ensure their reliable and safe operation. Designing reliable protection mechanism, however, is not a trivial task, as many practical issues need to be considered. The operation mode of MGs, which can be grid-connected or islanded, employed control strategy and practical limitations of the power electronic converters that are utilized to interface renewable energy sources and the grid, are some of the practical constraints that make fault detection, classification, and coordination in MGs different from legacy grid protection. This article aims to present the state-of-the-art of the latest research and developments, including the challenges and issues in the field of AC MG protection. A broad overview of the available fault detection, fault classification, and fault location techniques for AC MG protection and coordination are presented. Moreover, the available methods are classified, and their advantages and disadvantages are discussed.
\end{abstract}

Keywords: coordination techniques; fault detection; Microgrids; protection techniques

\section{Introduction}

In the past decades, the high demand for energy and increased proliferation of renewable energy resources (RESs) like photovoltaic (PV), wind turbines, and fuel cells have gained significant attention worldwide. The integration of renewable and conventional distributed energy resources (DERs) like PV, wind turbine, fuel cell, micro-turbine, and energy storage devices (ESS) develops the idea of microgrids (MGs). The US Department of Energy and IEEE std. 2030.7-2017 describes that microgrids are a group of DERs and interconnected loads with a clearly defined electrical boundary that acts as a single controllable entity with respect to the grid. It can connect and disconnect from the grid to allow it to function in both grid-connected and island modes of operation [1,2]. MGs are comprised of distributed generation, storage, load, and controlled interfaces. Overall, MGs may be regarded as centrally controlled entities that can be operated in gird/islanded-connected mode to enhance the quality, reliability, and availability of the power supply in a defined area [3,4]. MGs are regarded as promising and essential components of the future smart grid [5].

MGs can be classified as alternating current (AC), direct current (DC), and hybrid AC/DC MGs, based upon the type of distribution system. Due to the prevailing nature of the legacy AC power system and large market availability of AC loads, AC MGs are the subject of keen interest. Figure 1 illustrates the typical structure of an AC MG having RES-based generation, AC loads, ESS interfaced via a DC/AC converter, and interconnection to the utility grid via point of common coupling (PCC). As highlighted by the boundary, it may operate in the grid-connected and islanded mode of operation. 


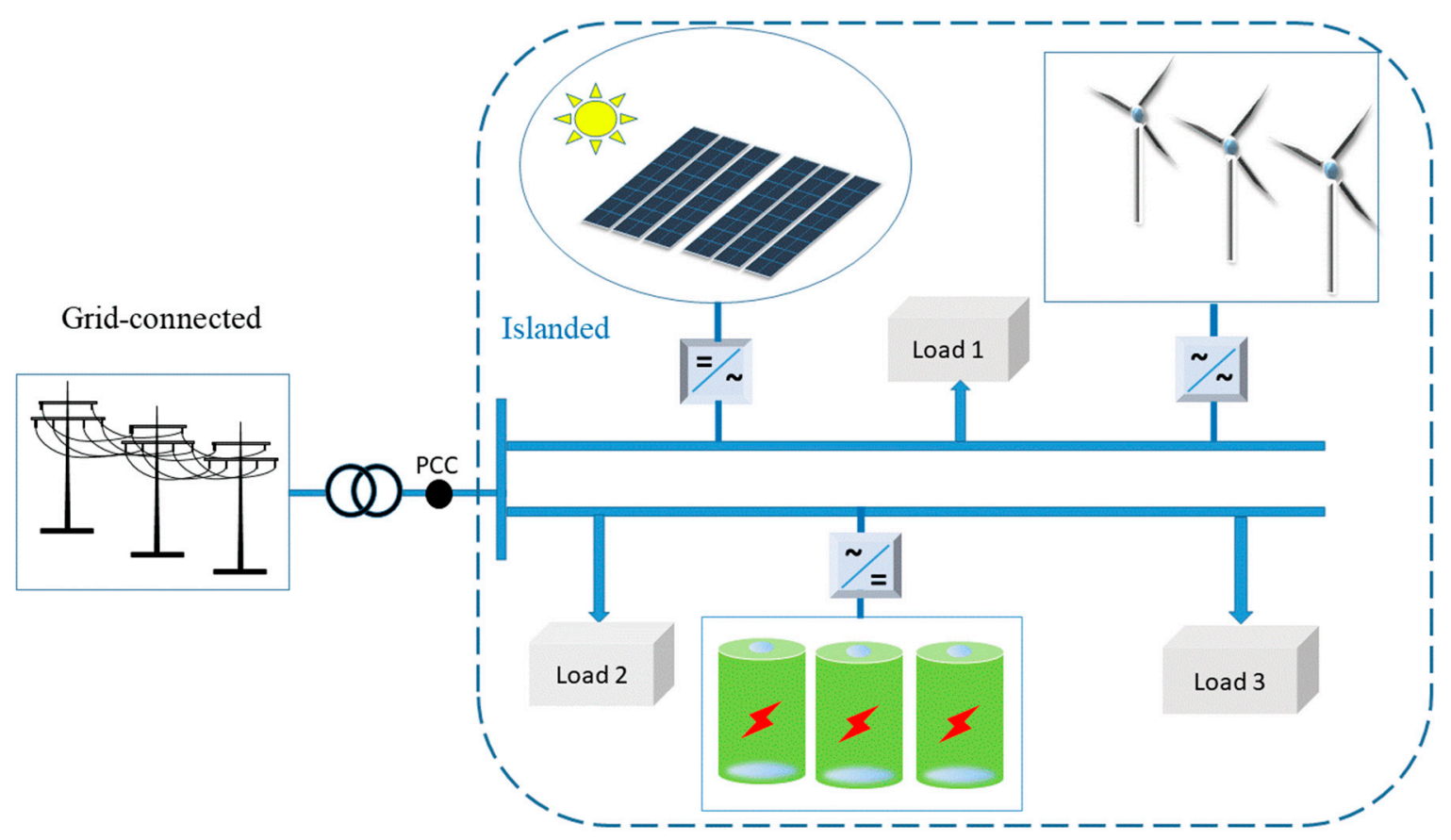

Figure 1. Typical structure of an alternating current (AC) microgrid (MGs) system.

MGs are being used to generate and store energy close to the consumer premises to avoid power flow in large transmission lines coming from a centralized power station. The drawbacks of such long-distance transmission lines include losses in terms of energy, voltage collapse, power quality, and lower reliability [6]. On the other hand, MGs provide several potential benefits, including enhanced system reliability, power quality, energy efficiency, economic and reduced carbon emission [7-9]. However, various operational challenges and technical issues have initiated due to increased utilization and integration of MGs in the distribution system network (DSN). Control of voltage, frequency, active and reactive power, power-sharing, energy management among DERs and connected loads, protection, system stability are major issues and challenges that need to be investigated for the reliable and cost-effective operation of MGs. Out of all these major issues, the protection of MGs is of prime importance to ensure its reliable and safe operation [10].

The protection of MGs is a complex and challenging issue due to their dynamic operational characteristics. The main challenges face a MGs protection system are two modes, i.e. grid-connected and islanded, bidirectional power flow, and intermittent nature of RESs resulting in varying levels of fault current contribution [11]. Moreover, the protection of islanded MGs is even more challenging due to the low level of short circuit current and due to changing network topologies. Further, the aim of the MGs protection system must be to respond to the fault in its two modes of operation such as grid and islanded modes of operation. For instance, if MGs are operating in the grid-connected mode of operation and a fault occurs on the grid side, the protection system must be capable of identifying a fault, switching the MGs system to its islanded mode of operation, and continuing supply to the connected loads. During a fault in the MGs, its islanded mode of operation, fault detection, and protection scheme must be capable of isolating the minimum faulty section. Traditional protection schemes in legacy power systems are generally designed for static conditions and radial configurations. These schemes do not take into consideration the varying operational characteristics, bidirectional power flow and changing network configurations of the MGs and therefore are not reliable for the protection of MGs.

Most conventional protection schemes are based on a high level of fault current or short current contribution from synchronous generators (SGs) and centralized power generation. MGs commonly consist of power electronics-based inverter interface distributed energy resources (IIDERs). Due to the stochastic and intermittent behavior of RESs, it is challenging to estimate the appropriate levels of 
fault current [12]. In addition, the fault current characteristics of IIDERs are different as compared to conventional SGs. The low level of fault current such as (1.2 2 and 2 3) times of the rated current, because of the inverter controller design [13-19]. However, the conventional SG have a fault current level accordingly $(4 \sim 10)$ times to the rated current $[16,20]$. Therefore, in the case of MGs, IIDERs limit the level of the fault current, thereby making fault detection less obvious based upon the current level only.

Increased integration of DERs impact the fault current from the grid, which consequently results due to the DGs connection and disconnection, which may consequently affect the settings of the protection system and protection devices (PDs) [21,22]. In addition, factors like the disconnection of DGs in the MGs system "plug and play" characteristics, including high impedance fault (HIF) result in a malfunction of protective relays [12]. The impact of DGs on DSN protection coordination has been reported [10,21-23]. Moreover, the integration of DERs in the existing DSN may result in short circuit current contributions that derive from different paths than the central connection point and cause blinding and sympathetic tripping [24,25]. Therefore, the traditional protection schemes could be ineffective for the protection of MGs prominently due to various factors and challenges that obstruct the MGs protection system as reported [11,21,22,26-29]. Figure 2 shows various major challenges of MGs protection.

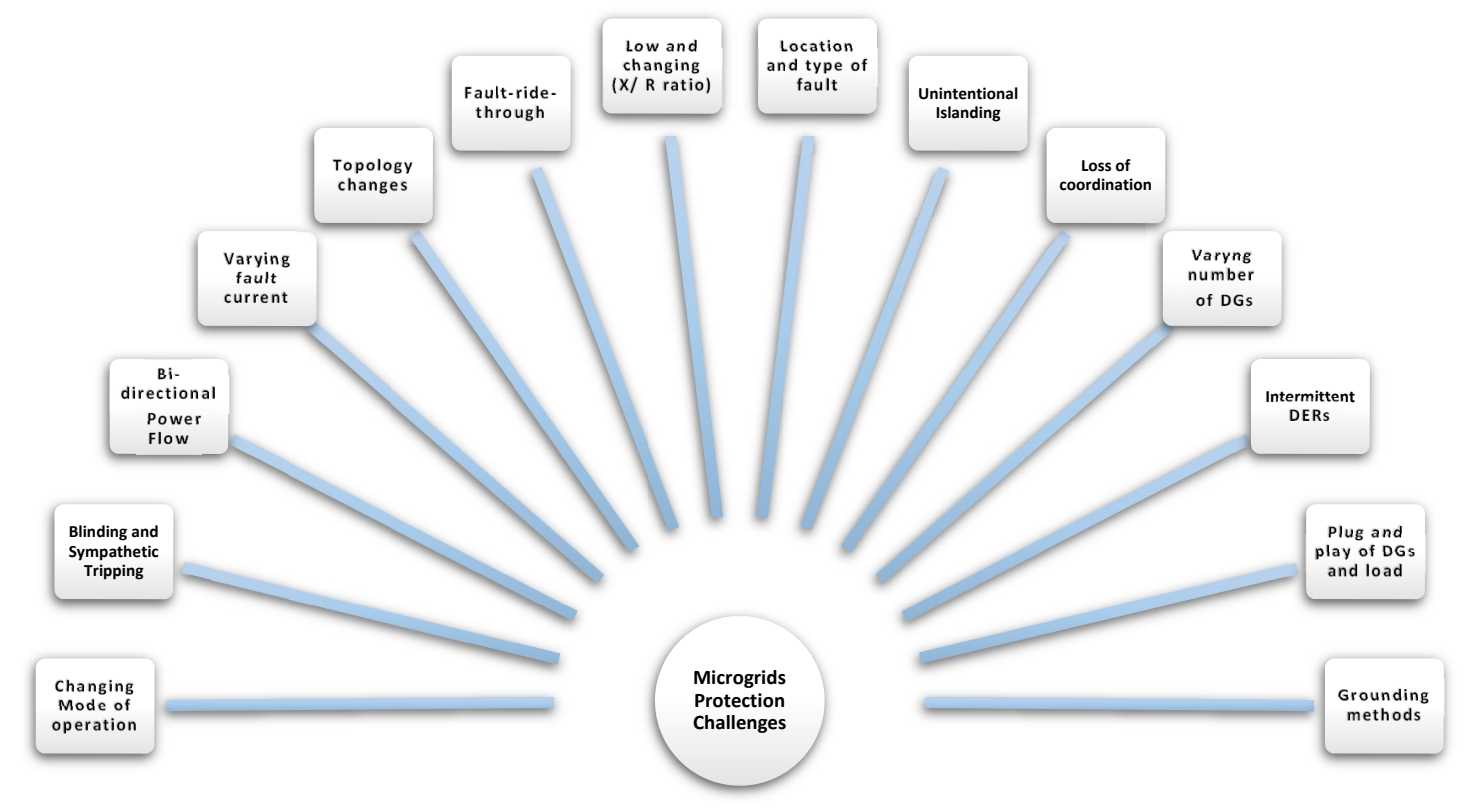

Figure 2. Protection challenges of the MGs system.

To overcome the above-mentioned issues and challenges, various fast and intelligent fault detections and classifications, including localization, fault direction identification, protection, and coordination schemes, have been investigated and proposed by different researchers. Fault diagnosis mainly depends on fault detection, isolation, and identification [30]. Fault detection with protection techniques based on sequence components has been proposed utilizing a positive sequence component [31] and zero-sequence component [18]. Ustun et al. [32], the MG protection system based on a centralized coordinated protection unit along with a communication system. Ustun et al. [33] proposed a hybrid adaptive and differential protection method. However, the high cost and communication network failure are the main problem of such techniques. The wavelet transform (WT) and data-mining-based fault detection and protection system are proposed by Mishra et al. [34]. Recently, artificial intelligence (AI) and machine learning (ML)-based protection techniques for fault detection, and fault classification and its identification of MGs topology are being investigated. Lin, $\mathrm{H}$ et al. [35] proposed an AI and support vector machine (SVM)-based technique. In an ML-based 
approach for fault classification in MGs is presented and proposed by, Abdelgayed et al. in [36]. Discrete wavelet transform (DWT) in conjunction with a deep neural network (DNN) protection technique is proposed by James et al. in [37] for fault detection, classification, and phase identification. Additionally, Susmita Kar et al. [38] proposed a differential protection approach based on Decision Tree (DT) and Fuzzy Logic (FL) for MGs fault detection and fault classification.

Adaptive protection of the MG system based upon a fast recursive discrete Fourier transform (FRDFT) algorithm with a Fuzzy logic (FL) module is presented to detect faults, including the optimal setting of a numerical relay [39]. Moreover, adaptive operation and protection utilizing intelligent electronic devices (IEDs) and an IEC 61850 standard-based communication system are proposed $[28,40,41]$. The protection coordination technique is being used to adjust and minimize the operation time of the primary and backup relay for reliable and selective protection. Different types of numerical, analytical, and heuristic-based algorithms are being used to minimize the coordination time interval (CTI) between the primary and backup relay. Sharaf et al. [42] presented protection coordination of the directional overcurrent relay (DOCR). Najy et al. [43], formulated the protection coordination problem (PCP) as non-linear programming (NLP) for DOCR, and it was solved using the genetic algorithm (GA). A hybrid optimization approach, such as GA with particle swarm optimization (PSO), is used to minimize the CTI [44]. In addition, several review and survey papers on AC, DC, and hybrid AC/DC MG protection and coordination techniques already exist in the literature. Protection challenges and issues and recent developments for AC and DC MGs are presented $[25,45,46]$. Protection challenges including DC fault detection, location, and isolation in DC and MGs are reviewed in $[47,48]$. Furthermore, hybrid AC/DC MG structures, operational challenges, protection issues, and developments are reviewed in [49-51]. Table 1. provides a summary of the review papers and lists their major contributions. However, to the best of our knowledge, while these papers present protection issues and challenges, including the categorization of protection and coordination techniques, some concerns, such as fault detection, localization, and fault direction identification in AC MGs, have not been addressed or classified properly. Therefore, this paper presents a detailed state-of-the-art on recent developments and challenges in AC MG protection considering fault detection and classification, fault localization, fault direction identification, and protection coordination. Alternatively, this work will also be useful to present a holistic overview of the fault detection and protection of AC MGs. The major contributions of this paper are highlighted as follows:

- Different fault detection and classification techniques are reviewed and investigated mainly considering signal processing, knowledge, and model-based methods.

- Challenges in fault localization and direction identification in AC MGs are reviewed.

- A detailed state-of-the-art on different MGs protection strategies along with communicationassisted adaptive techniques and multi-MG systems are presented.

- Protection coordination for MGs is reviewed and examined.

The organization of the paper is as follows: Section 2 presents fault detection, classification, location, and direction identification methods. In Section 3, protection strategies are discussed. The protection coordination techniques are presented in Section 4 . Furthermore, a brief discussion of the solutions and future directions following the conclusion is given in Sections 5 and 6, respectively. 
Table 1. Summary of few existing review articles for MG protection.

\begin{tabular}{|c|c|}
\hline Reference & Contribution \\
\hline $\begin{array}{l}\text { Beheshtaein et al. and } \\
\text { Mirsaeidi et al. [25,46] }\end{array}$ & $\begin{array}{c}\mathrm{AC} \text { and DC MG protection challenges and issues, recent } \\
\text { development techniques, and future trends }\end{array}$ \\
\hline $\begin{array}{l}\text { Waqas javed and } \\
\text { Beheshtaein et al. }[47,48]\end{array}$ & DC MGs protection issues and recent development \\
\hline Mirsaeidi et al. and Sarangi at al. [49-51] & $\begin{array}{c}\text { Protection of hybrid AC/DC Microgrids, issues, development and } \\
\text { future directions }\end{array}$ \\
\hline Barra et al. [52] & Adaptive protection of MGs, DSN, and DGs \\
\hline Telukunta et al. [21] & $\begin{array}{l}\text { Protection technique for renewable integrated power network, such } \\
\text { as transmission, distribution including advantages and limitations }\end{array}$ \\
\hline $\begin{array}{l}\text { Brearley et al. and } \\
\text { Mirsaeidi et al. }[53,54]\end{array}$ & Protection methods, issues and challenges \\
\hline Hooshyar et al. [55] & $\begin{array}{c}\text { Protection techniques for different types of the relay by considering } \\
\text { various fault and generation conditions }\end{array}$ \\
\hline Manditereza et al. [56] & $\begin{array}{l}\text { Integration effects of DGs on DNS protection performance and } \\
\text { technical issues }\end{array}$ \\
\hline Habib et al. [57] & Communication system failure impact of adaptive protection \\
\hline Hosseini et al. [58] & $\begin{array}{l}\text { The recent development in MGs protection including MGs structure, } \\
\text { and protection challenges for DG and DSN }\end{array}$ \\
\hline Memon, et al. [59] & AC MGs protection technique, challenges, and issues \\
\hline $\begin{array}{l}\text { Gopalan et al. and } \\
\text { Haron et al. and Ibrahim Almutairy [60-62] }\end{array}$ & Coordination strategies and protection schemes \\
\hline Basak et al. [63] & Control, protection and stability of Microgrids \\
\hline
\end{tabular}

\section{Categorization of Fault Detection and Classification, Localization, and Direction Identification Techniques}

\subsection{Fault Detection and Classification Methods}

The main and key function of a protection scheme is to recognize and detect fault occurrence. Various fault detection and protection techniques have been used for fault detection in transmission lines (TL) and DSN such as overcurrent, differential, and distance/impedance-based techniques. However, due to the integration of DERs and MGs in the DSN, conventional methods of fault detection and classification cannot be directly applied $[15,20,64,65]$. Alternatively, these schemes need to be modified according to the constraints offered by the dynamically changing network and generation conditions. Recently, various methods have been reported in the literature to detect faults in MGs. Accordingly, this paper has categorized the available schemes for fault detection and classification (FDC) of AC-MGs based on employed techniques, such as signal processing based FDC, knowledge-based FDC (AI and ML-based) and model-based fault detection. A summary of different fault detection and classification methods based on signal-processing-based FDC techniques is provided in Table 2.

\subsubsection{Signal-Processing-Based Fault Detection and Classification (FDC) Methods}

Different digital signal processing (DSP)-based fault detection techniques are being utilized for transmission lines and distribution systems, including MGs. During a fault condition, the system parameters change from normal values, and the system output changes accordingly. The output signal pattern or feature correlates with the system faults [66]. The features of interest for fault detection are extracted for pattern analysis such as in the time domain, frequency domain, or in the combination of time-frequency-based methods [30]. Various digital signal processing methods have been used to detect faults in MGs; they include Wavelet transform (WT) [67], fast Fourier transform (FFT) [68], S-transform [69], and Hilbert-Huang transform (HHT) [70]. Stanisavljević et al. [71] presented a comprehensive review of different DSP-based techniques for voltage disturbance detection in the distribution system with DGs. However, in this current review paper, many DSP-based fault detection methods, as well as fault classification techniques, are presented for MGs. Various signal-processing-based fault detection and classification methods are given in Figure 3. 


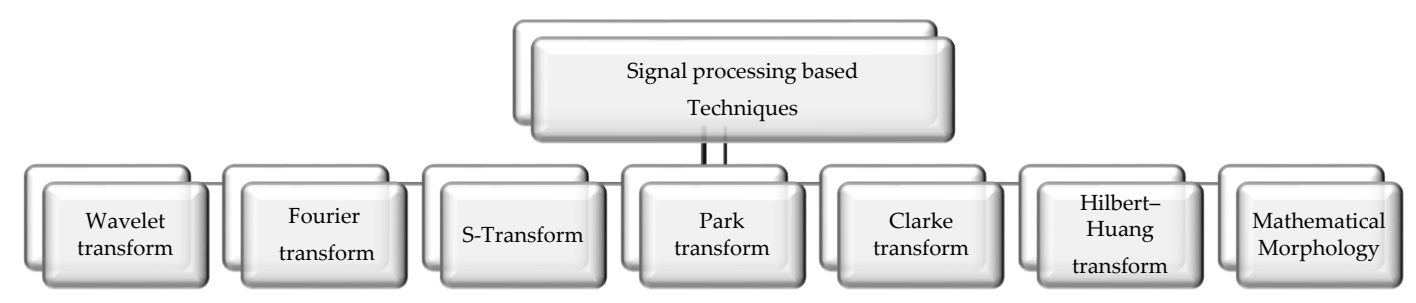

Figure 3. Signal processing-based fault detection and classification methods.

Wavelet Transform

WT-based fault detection is extensively used for fault study, power system protection, power system disturbance, and power quality assessment in the transmission line or DSN, including MGs and multi-MG systems. WT is effectively used to analyze the transients in a signal (like current and voltage) that are related to the fault in both the time and frequency domains. WT is used to translate time-domain functions that are localized in time-frequency [67]. A signal can be decomposed and parametrized by WT in time and frequency localized signals. The parametrized content of the low frequency single are known "approximations" and the high frequency single content are called as "details" [72,73]. WT is widely used in various DSP applications like filtering, image compression, and de-noising [74]. A WT-based power quality monitoring system has been proposed for the identification of transient disturbances [75]. Abdelgayed et al. [76] proposed a WT function-based fault feature extraction and machine-learning-based fault classification for MG protection. The proposed method based on the pursuit of an optimal wavelet function match and the best combination of WT functions are selected by PSO for selecting the useful features for fault detection in transient signals.

Netsanet et al. [77] employed signal-processing-based windowed Wavelet transform (WWT) technique for fault detection along with fault classification in MGs. WWT is applied to compute some of the useful features of the signal from local voltage and current branches. Useful features extracted by WWT are then used as an input for bagged DT for fault detection and classification. A WT and data-mining-based technique is proposed for MGs fault detection along with its fault classification [34]. The measured current signals at the relay points are pre-processed by WT in order to extract useful features such as; (a) change in the energy, (b) entropy, and (c) standard deviation. Furthermore, these useful features are utilized as input to build the training set of a DT module for fault detection/classification. Dehghan et al. [78] proposed fast fault detection/ classification method. In this proposed method, the positive sequence current components at the PCC are measured and used to calculate coefficients of WT with the singular value matrices as well as the expected entropy values applying a stochastic process. Fault detection/classification based upon the indices defined by the WT singular entropy are presented in the positive sequence components and the three-phase current. Saleh et al. [72] proposed a digital protection method, that based on the wavelet packet transform (WPT). In this method, the high-frequency components that are existing in the synchronous reference frame (d-q axis) are extracted by using WPT. Next, the WPT coefficients are used to detect and identify faults for islanded and grid-connected operation [72,73].

\section{Fast Fourier Transform (FFT) and Discrete Fourier Transform (DFT)}

An adaptive numerical relay approach by using a fast recursive discrete Fourier transform (FRDFT) algorithm is presented for fault detection by Dhivya Sampath Kumar et al. [39]. The presented algorithm, in conjunction with the directional element, is applied to adjust the relay setting for the grid and islanded mode of MGs. Chaitanya et al. [68] proposed an adaptive communication-assisted FL-based protection technique for MG fault detection and classification. Initially, useful features are extracted using a recursive DFT and sequence analyzer. In this method, the phasor and sequence components of the current signals are measured and then used as the input features of the FL-based module to detect and classify a fault condition. Susmita Kar et al. [38] presented a DFT-based fault feature extraction for MGs protection. The extracted features by DFT are (a) amplitude, (b) phase 
angle, and (c) frequency of the voltage and current signals. Next, these features are used to compute differential features at each end of the feeder. The data-mining model is applied to detecting a fault event. However, the differential protection is reliable for fault detection, but it increases the cost, including current transformer (CT) error, in measurement and CT saturation needs to be considered.

\section{S-Transform}

S-transform is another signal processing technique and that is an extension of the WT and short-term Fourier transform. S-transform provides a time-frequency representation of a signal along with a frequency-dependent resolution [79,80]. Moreover, it is known as a special case of short term Fourier transform by Gaussian window function [81]. The main advantage of S-transform is that it provides a multi-resolution analysis (MRA), preserved for the entire phase of single frequency components [69]. Susmita Kar et al. [38] used S-transform to pre-process measured local current signals of a MGs distribution feeder to extract useful statistical features like the mean, entropy of time-frequency contour, and standard deviation energy. Next, the extracted useful features are applied to build input for DT-FL-based rules for fault detection/classifications. Susmita Kar et al. [69] proposed a differential protection technique that is based on S-transform. In this method, the feeder currents are measured at both ends and are pre-processed with S-transform to generate time and frequency contours. Next, time-frequency contours of the spectral energy are computed, and the differential spectral energy is measured to recognize a fault condition. The proposed protection technique is used to test different faults in a varying network configuration of MGs.

Hilbert-Huang Transform (HHT)-Based Fault Feature Selection

Hilbert-Huang transform (HHT) was developed by NASA. It is a signal processing technique used to analyze the nonlinear, including non-stationary data, by the empirical mode decomposition (EMD) technique using an intrinsic mode function (IMF) [82]. The decomposition method utilized by HHT is adaptive and efficient. In several research studies, the HHT is implemented for fault study that including the TL, DSN and MGs. Mishra et al. [83] presented HHT, in conjunction with an ML-based approach, to identify the fault conditions in MGs. Initially, the phase current at different locations is measured and is applied to the EMD method to compute different IMFs differential features. Next, these features are applied to HHT as input to the ML model for fault identification and classification. Gururani et al. [80] proposed a HHT-based differential protection technique for MGs protection.

\section{Park and Clark Transform Based Fault Detection}

Park transform is used to convert the time domain three-phase $(a b c)$ frame to direct, quadrature and zero components $(d q 0)$ (DC components) in a rotating reference frame. Clark transform is used to convert a three-phase reference frame to a stationary $(\alpha \beta 0)$ reference. An MG control system is normally designed using Park and Clark transforms. However, the controller response of these transforms under fault condition are analyzed in $[19,84]$. Thattai et al. [70] presented fault detection method based on Park vector trajectory and HHT for MGs. WT in conjunction with Park transform is used to detect a fault in MGs is proposed by Escudero et al. [85]. Moreover, during healthy conditions, the park vector trajectory is a circle, and its eccentricity is near to zero. However, the vector trajectory eccentricity may be increased with the level of fault [86]. Fault detection in MGs with varying topology is based on Clarke and S-transforms to characterize the transients in the voltage and current signals during a fault. Useful extracted features of the waveform are used to form the appropriate indices for fault detection, location, and characterization.

\section{Mathematical-Morphology-Based Fault Detection}

Mathematical morphology (MM) is another signal processing method that shapes the signal in time-domain. Various fundamental MM operators use MM filters to extract features from a signal. The MM filtering operators are based on the erosion and dilation, including the opening-closing- 
difference filter. The main advantages of MM are (a) it is fast and simple, (b) it is applicable to non-periodic transient signals, (c) the sampling windowing size is small, and (d) it can extract signal features accurately [87]. MM with an ML-based approach is implemented for fault detection along with fault classification [88]. Fault detection and localization by MM inclusion of recursive least-square (RLS) techniques are proposed for the detection and localization of a fault [89]. In this method, the MM based dilation and erosion median filter (DEMF) is applied to identify and classify the faulty conditions. Furthermore, the fault location is identified and estimated by RLS. Li et al. [90] proposed $\mathrm{MM}$ and traveling-wave-based protection techniques for IIDERs-based MGs.

Table 2. Fault detection and protection scheme using signal processing based methods.

\begin{tabular}{|c|c|c|c|}
\hline Methods & Fault detection features & Advantages & Limitation \\
\hline $\begin{array}{l}\text { WWT and Decision Tree } \\
\text { [77] }\end{array}$ & $\begin{array}{l}\text { - WWT is used to compute } \\
\text { Approximation, Detail, and the } \\
\text { peak value of the } \\
\text { WT coefficient }\end{array}$ & $\begin{array}{ll}\text { - } & \text { Fast } \\
\text { - } & \text { Intelligent } \\
\text { - } & \text { High accuracy about } \\
& \text { accuracy is } 92.1 \%\end{array}$ & $\begin{array}{l}\text { - } \quad \text { Limited time } \\
\text { resolution capability } \\
\text { low performance for high } \\
\text { impedance faults } \\
\text { - } \quad \text { Complex due to the increased } \\
\text { number of features }\end{array}$ \\
\hline DWT and DNN [37] & $\begin{array}{ll}\text { - } & \text { WT coefficient } \\
\text { - } & \text { Min and max value } \\
\text { - } & \text { Mean } \\
\text { - } & \text { Standard deviation } \\
\text { - } & \text { Skewness } \\
\text { - } & \text { Energy of coefficient } \\
\text { - } & \text { DNN }\end{array}$ & $\begin{array}{l}\text { - Intelligent and fast fault } \\
\text { detection, classification } \\
\text { and phase identification } \\
\text { - } \quad \text { DWT and DNN } \\
\text { - Without } \\
\text { - } \quad \text { High communication } \\
\text { - }\end{array}$ & $\begin{array}{l}\text { - HIF is not given. } \\
\text { - } \quad \text { Topology not consider } \\
\text { - } \quad \text { A great number of feature } \\
\text { and data } \\
\text { - } \quad \text { complex } \\
\text { - High computational burden }\end{array}$ \\
\hline S-transform [69] & - $\quad$ spectral energy & $\begin{array}{ll}\text { - } & \text { Detect shunt faults } \\
\text { - } & \text { Fast HIFs } \\
\text { - } & \text { Better } \\
\text { anti-noise performance }\end{array}$ & $\begin{array}{l}\text { - Fault location and classification } \\
\text { are not considered }\end{array}$ \\
\hline $\begin{array}{c}\text { Differential and } \\
\text { Hilbert-Huang } \\
\text { Transform (HHT) [80] }\end{array}$ & $\begin{array}{l}\text { - } \\
\text { - } \\
\text { the difference in } \\
\text { spectral energy }\end{array}$ & $\begin{array}{ll}\text { - } & \text { Efficient } \\
\text { - } & \text { Detect HIF } \\
\text { - } & \text { Anti-noise performance }\end{array}$ & $\begin{array}{l}\text { - } \quad \text { Costly } \\
\text { - } \quad \text { The fault direction is not given }\end{array}$ \\
\hline $\begin{array}{c}\text { Mathematical } \\
\text { Morphology (MM) } \\
\text { Recursive Least-Square } \\
\text { (RLS) [89] }\end{array}$ & $\begin{array}{ll}\text { - } & \text { Dilation and erosion } \\
\text { - } & \text { Zero-sequence currents } \\
\text { - } & \text { RLS method }\end{array}$ & $\begin{array}{ll}- & \text { Fast } \\
\text { - } & \text { Accurate fault } \\
& \text { localization } \\
& \text { and classification }\end{array}$ & $\begin{array}{l}\text { - } \quad \text { HIF detection are } \\
\text { not considered } \\
\text { - } \quad \text { High calculation burden }\end{array}$ \\
\hline $\begin{array}{l}\text { WT and Shannon } \\
\text { Entropy [83] }\end{array}$ & $\begin{array}{ll}\text { - } & \text { Shannon entropy } \\
\text { - } & \text { Fuzzy logic }\end{array}$ & - $\quad$ Fast & $\begin{array}{l}\text { Fault direction, localization, } \\
\text { and HIF are not included }\end{array}$ \\
\hline DWT [91] & $\begin{array}{l}\text { - } \quad \text { Detail and approximation } \\
\text { - HIF detection }\end{array}$ & $\begin{array}{ll}\text { - } & \text { Efficient } \\
\text { - } & \text { HIF faults are identified }\end{array}$ & $\begin{array}{l}\text { - Fault direction and } \\
\text { classification is not considered } \\
\text { - The computational burden } \\
\text { is high }\end{array}$ \\
\hline DFT and DT [38] & $\begin{array}{l}\text { - } \\
\text { - } \\
\text { DT and SVM }\end{array}$ & $\begin{array}{ll}\text { - } & \text { Fast and intelligent } \\
\text { - } & \text { High Performance }\end{array}$ & $\begin{array}{l}\text { - Fault location, HIF and } \\
\text { topology changes are not given }\end{array}$ \\
\hline
\end{tabular}


2.1.2. Knowledge-Based FDC (Artificial Intelligence and Machine learning -Based Fault Detection and Protection Methods)

Recently, various AI and ML-based fault detection and classification techniques, such as ANN, fuzzy-rule-based, DNN, hybrid ANN-FL, adaptive network-based fuzzy inference system (ANFIS), SVM, and DT, have been utilized for MGs protection. Efficient fault detection, as well as its classification approaches, are required in an MG protection system to facilitate quick repairs, including restoration of the network, to reduce interruption time. However, AI and ML-based technique performance and their computational time need to be considered for fast and robust fault detection and classification for the MGs system. Different AI and ML-based fault detection and classification techniques are reported in various studies are given in Figure 4. Moreover, Table 3 provides a summary of some knowledge-based FDC for MGs.

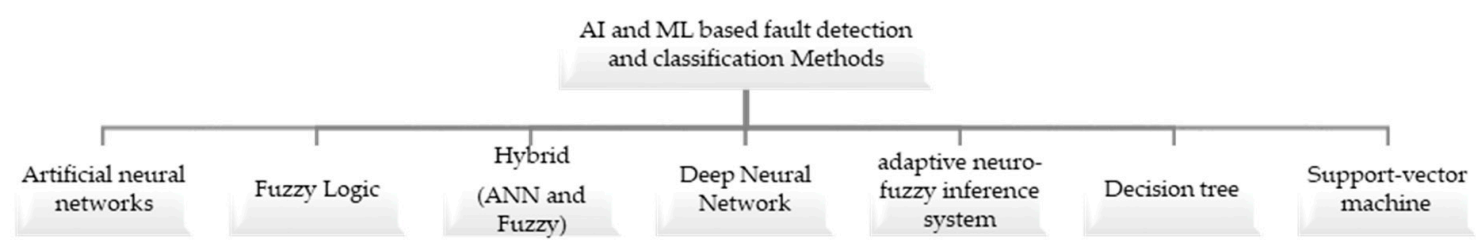

Figure 4. Knowledge-based fault detection and classification (FDC) techniques.

Fuzzy Logic Based Methods

Bukhari et al. [92] proposed a fuzzy logic (FL)-based MG fault detection and its classification method. In this study, an interval of type-2 FL for different uncertainties related to fault detection, location, and classification in MGs are presented. Chaitanya et al. [68] used an intelligent FL-based approach for fault detection and classification for DSN with integrated DGs. Two different FL interface systems are used to identify HIF fault for each phase. Useful features are extracted by using the Teager energy operator for Fault detection. Dhivya Sampath Kumar et al. [39] proposed a FL-based decision-making module with FRDFT is implemented to detect and update the protection setting of the adaptive overcurrent relay. Susmita Kar et al. [38] used a DT-induced FL rule-based approach is proposed to set the relaying decision that consisted of fault detection in conjunction with the classification module. Netsanet et al. [77] proposed a FL-based adaptive with bagged DT protective relaying technique for MGs for fault detection and fault classification. Fuzzy-neuro based fault classification used for transmission line (TL) [93].

\section{Artificial Neural Network (ANN)-Based Methods}

Fault detection, including its classification and phase identification for MGs, is proposed using DWT and DNN [37]. First, the DWT is applied to compute the useful feature from local phase current measurements. Next, the useful extracted features are used as input for three DNNs to detect, classify, and identification of faulty phase and location. Lin, $\mathrm{H}$ et al. [35] proposed a hybrid ANN-SVM-supported adaptive protection scheme. The ANN model is used to detect and identify a fault in a line and its location is estimated is by using SVM. Hong Y.et al. [94] used the DWT-ANIFS approach to detect and identify a faulty zone. Moreover, the ANFIS-based decision module sets the operation of the circuit breaker and recognizes a faulty zone in the MGs system. Wang et al. [95], proposed a deep convolutional neural network (DCNN)-based fault and classification (including power quality disturbance in MGs and multi-MGs) system. Power quality problems caused by DGs and nonlinear load (including faults and mode of operation) are considered in this study. To validate the effectiveness of the presented technique, the obtained results are observed and analyzed with some other DNNs in terms of accuracy, training time, and model size. 
Machine-Learning-Based Methods

Machine learning (ML)-based on fault classification like DT and KNN is proposed to classify the faults of MGs [36]. Hamid Reza et al. [96] proposed and presented an islanding detection method including the grid fault detection for active DSN by utilizing SVM. Casagrande et al. [20] used two different fault classifiers such as DT in conjunction with naive Bayes (NB). The performance of both classifiers is compared and evaluated. It was determined that DT has a better performance for fault classification compared to NB. Tamer S. Abdelgayed et al. [76] proposed and presented fault detection/classification for MGs by applying four different ML-based techniques such as DT, k-nearest neighbor (k-NN), SVM, and naive Bayes (NB) classifier are presented for islanded and grid-connected operation. The above-mention ML-based fault classification techniques are compared and evaluated by implementing a Monte Carlo (MC)-stratified cross-validation technique. The of K-NN was outstanding, with $95.63 \%$ accuracy. S. samantaray et al. [97], proposed a fault detection and classification method for flexible AC TL and the proposed method based on upon DT.

Table 3. Artificial Intelligence (AI) and Machine learning (ML) -based fault detection and fault classification methods.

\begin{tabular}{|c|c|c|c|}
\hline Methods & Features & Advantages & Limitations \\
\hline $\begin{array}{l}\text { Fuzzy interface systems } \\
\text { (FISs) [68] }\end{array}$ & $\begin{array}{l}\text { - } \quad \text { Teager Energy operator } \\
\text { - } \quad \text { Two FISs }\end{array}$ & $\begin{array}{l}\text { - } \quad \text { The response time } 1 / 4 \\
-1 \text { cycle. } \\
\text { - } \quad \text { Fault detection/classification } \\
\text { - } \quad \text { HIF detection }\end{array}$ & $\begin{array}{l}\text { - Fault localization and } \\
\text { topology changes are } \\
\text { not considered } \\
\text { - complex in nature }\end{array}$ \\
\hline $\begin{array}{l}\text { Discreet Wavelet (WT) } \\
\text { and (ANFIS) [94] }\end{array}$ & $\begin{array}{l}\text { - } \quad \text { energy coefficient } \\
\text { ANFIS is used to identify the } \\
\text { fault zone }\end{array}$ & $\begin{array}{ll}\text { - } & \text { Fast and intelligent } \\
\text { - } & \text { Response time is } 1 / 4 \text { cycle }\end{array}$ & $\begin{array}{ll}\text { - } & \text { complex computation } \\
\text { - } & \text { Large data set } \\
\text { - } & \text { Fault classification } \\
\text { - } & \text { HIF is not included } \\
\text { - } & \text { Islanded operation }\end{array}$ \\
\hline DT- Fuzzy Rule [38] & $\begin{array}{ll}\text { - } & \text { S-transform is used to } \\
\text { - } & \text { Enpute statistical features } \\
\text { - } & \text { Mean } \\
\text { - } & \text { Standard deviation } \\
\text { - } & \text { Entropy }\end{array}$ & - $\quad$ Fast & $\begin{array}{l}\text { - A large number of } \\
\text { the features } \\
\text { - } \quad \text { High computational burden } \\
\text { Fault location and HIF are } \\
\text { not consider }\end{array}$ \\
\hline Hybrid (ANN-SVM) [35] & $\begin{array}{l}\text { - Adaptive protection scheme } \\
\text { for MGs }\end{array}$ & $\begin{array}{ll}\text { - } & \text { Adaptive } \\
\text { - } & \text { Self-learning } \\
\text { - } & \text { Self-training } \\
\text { - } & \text { Fault location }\end{array}$ & $\begin{array}{l}\text { - } \\
\text { - } \quad \text { large number of data sets } \\
\text { - } \quad \text { High Computational burden } \\
\text { and training }\end{array}$ \\
\hline Fuzzy-Neuro [81] & $\begin{array}{ll}- & \text { Fuzzy-Neuro } \\
- & \text { Symmetrical components }\end{array}$ & $\begin{array}{ll}\text { - } & \text { Fast } \\
\text { - } & \text { Accurate } \\
\text { - } & \text { Robust }\end{array}$ & $\begin{array}{l}\text { - } \\
\text { threshork changes affect the } \\
\text { - } \quad \text { Compluex } \\
\text { - } \quad \text { Large fault data }\end{array}$ \\
\hline $\begin{array}{l}\text { Adaptive Fuzzy Logic } \\
\text { [68] }\end{array}$ & $\begin{array}{l}\text { - Zero sequence component of } \\
\text { current signals }\end{array}$ & $\begin{array}{ll}\text { - } & \text { Fault detection, classification } \\
\text { - } & \text { Phase identification } \\
\text { - } & \text { Dynamic changes }\end{array}$ & $\begin{array}{l}\text { - } \quad \text { Communication failure } \\
\text { - Costly due to } \\
\text { communication system } \\
\text { - HIF not included }\end{array}$ \\
\hline
\end{tabular}

\subsubsection{Model-Based Fault Detection and Identification}

Model-based fault detection and identification (FDI) methods are used to detect faults in systems such as MGs. Model-based FDI is based on analytical knowledge of the system and is mainly comprised of parameters estimation, the parity relationship method, and an observer/filter-based technique [66,98]. Al Hassan et al. [99] proposed a novel model-based FDI for MGs protection. In this proposed method, the mathematical transfer functions are derived for fault/non-fault conditions, and changes in MGs structure. Parameters such as voltage and current are used as the input and output of the system, respectively, to identify a fault occurrence. To distinguish fault/non-faulted conditions, 
the models under consideration produce an estimated current that is compared to the measured current in real-time. Hosseinzadeh et al. [100] used a model-based FDI has been to detect DC/DC converter faults in a wind turbine system. In this study, a filter was designed and proposed to detect the fault in the DC/DC converter. The proposed filter consists of an observer along with a residual signal generator. Jason Poon et al. [101] proposed a model-based FDI state estimator approach to detect faults in switching power converters. In this FDI method, a switched linear state estimator is used to generate a real-time error residual that distinguishes the measured and estimated output voltage and current. Hongwen He et al. [102] presented a model-based fault detection approach based on an adaptive extended Kalman filter, which detects and isolates faults in sensors that are used in a series of battery packs. Abdulhamed Hwas et al. [103] presented a quantitative model-based fault detection and isolation for a wind turbine. In this study, an observer is proposed for system modeling. The innovation signal of the observer is used to detect and identify the fault conditions. Seongpil Cho et al. [104] proposed and presented fault detection, isolation, and fault-tolerant control schemes by using model-based techniques when considering the blade pitch of a floating wind turbine. The Kalman filter is designed to estimate the blade pitch angle of the system to detect faults. Moreover, MGs and smart MG fault detection methods including model-based fault detection and its type are review in $[105,106]$ respectively. A comprehensive review of fault diagnosis and fault-tolerant techniques is presented, which is comprised of fault diagnosis using model-based and signal-based methods [30].

\subsection{Fault Location Detection}

Fault localization aims to identify the exact portion of the DSN and TL that is affected by the fault condition. The fault localization is a process to identify the exact location of a fault with the highest possible precision and accuracy [107]. Optimal fault location technique required to improve the reliability of the network and restoration of the system after a fault event [108]. The "IEEE Std C37. 114-2014" provided a guide for finding the location of the fault for both AC- TL and distribution lines [109]. Extensive research work has been done to locate a faulty section in the TL and DSN. Fault localization methods are classified based on (a) current and voltages signal at fundamental frequency mainly on impedance measurement, (b) traveling wave-based methods, (c) high-frequency component-based methods, and (d) knowledge-based methods [107,108]. The TL fault localization method is proposed based on the traveling wave [110] and SVM [111]. Mahdi Mirzaei et al. [112] proposed a fault location method for a series-compensated three-terminal TL by using DNNs.in this proposed method the DWT in combination with DNN is applied to recognize the faulty portion and its location in a series-compensated three-terminal TL. Rodrigo H. Salim et al. [113] proposed an impedance based fault localization for DSN. Figure 5 shows different fault location identifying techniques for MGs as reported in the literature.

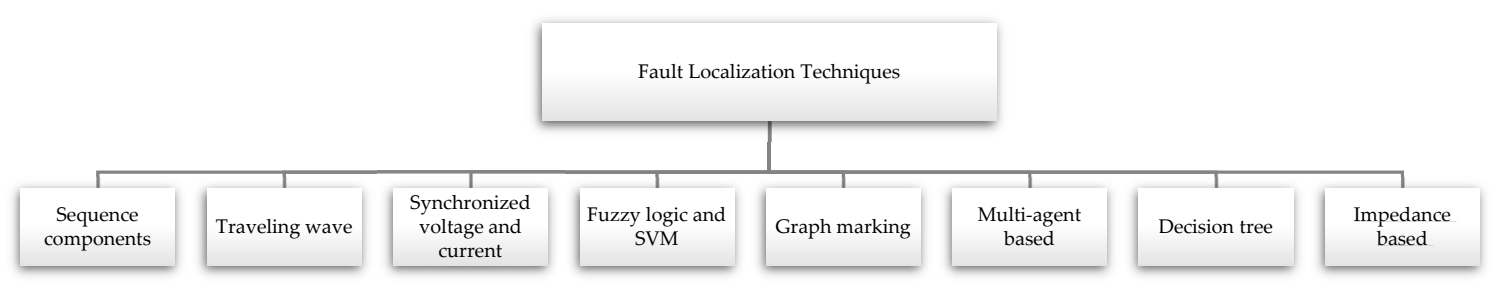

Figure 5. Fault location identifying techniques.

Due to increased DGs integration in DSN, fault localization becomes a complex and challenging issue. Sukumar M. Brahma et al. [114] reported that the fault localizing in DSN with DG is complicated due to various factors such as (a) varying conductor sizes, (b) multiple feeder taps, (c) multiphase laterals, (d) varying impedance, (e) unbalanced operation, and (f) fault at different locations consequently give 
rise to the same voltages and currents that are observed at the substation. Figure 6 . Shows various challenges for fault localization in MGs.

Siavash Beheshtaein et al. [115] proposed and presented a fault detection including the location in an AC-meshed MG. The presented fault localization scheme is used to inject a high-frequency harmonics signal to the faulty zone. After fault detection, the DGs inject a high-frequency harmonic signal at both ends of a line and compute the high-frequency impedance. The measurements of the high harmonic impedance are used as input to the multi-class SVM to recognize the exact location of a fault along with different operating conditions in AC meshed MGs. Izudin Džafić et al. [116] proposed and developed a downstream graph marking approach to identify and locate a fault in DSN. Yuanyuan Wang et al. [117] used a gray relation degree techniques to detect a faulty section in the feeder in a resonant-based grounding configuration. The fault localization criterion is set by the slope relation matrix to locate a fault in the faulty feeder.

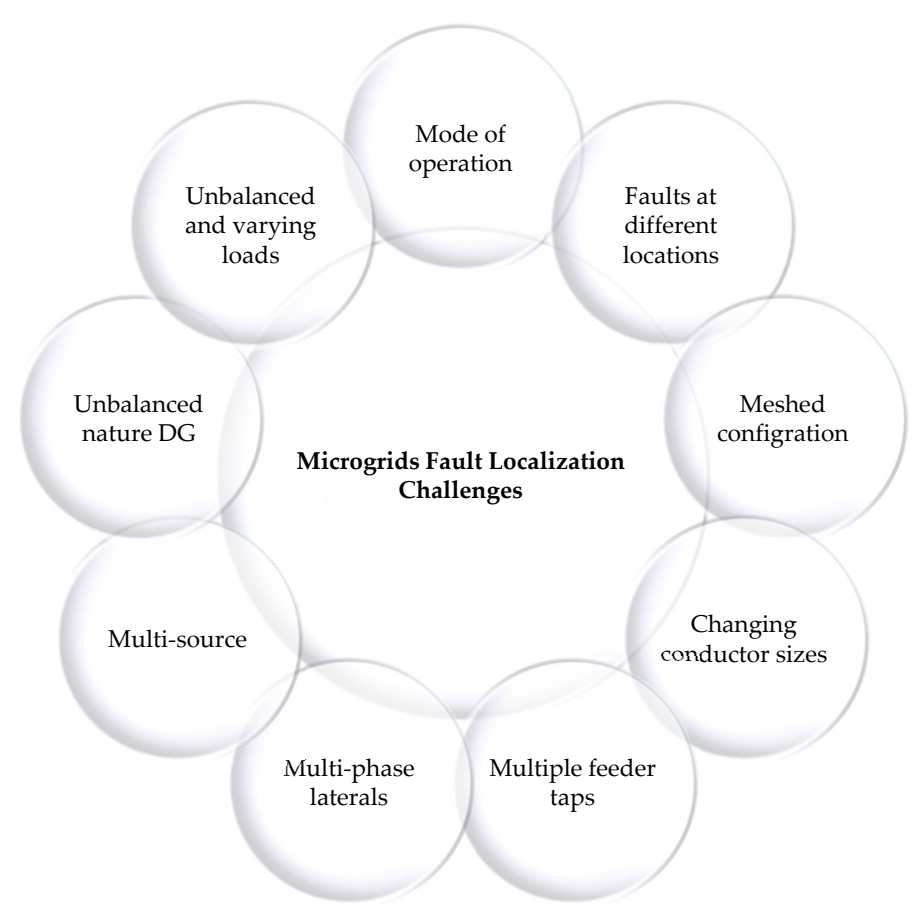

Figure 6. Fault location challenges of MGs.

The fault location method based on voltage and the current measured signal along with the synchronization at the interconnection of DG units are presented [114]. The fault location method is proposed for single-phase MGs. The transient voltage signal maximum oscillation of the fault signal utilized to identify the fault location [118]. A rule-based fault localization method is proposed for DSN [119]. Lei, Lei et al. [120] proposed a differential directional protection. In this technique, local measured current and voltage signals of one phase are used to calculate the differential direction. The study investigated the operation mode, including that the unbalanced load does not affect the set threshold for the fault location technique.

Oluleke. babayomi et al. [121] proposed and presented a fault identification and localization based on an adaptive neuro-fuzzy for the DSN. The fault data are collected from the network and are applied to train the fuzzy inference system to find out the location of the fault. A. Borghetti et al. [122] proposed a fault location method. The propose method based on the WT decompositions of voltage transients are related to the traveling waves for DSN. Hany F. Habib et al. [123] proposed a multi-agent-based (MAB) fault localization method. In this technique, the distributed agents are used to locate a fault position. Amir Farughian et al. [124] presented a fault localization method for non-effectively earthed medium voltage DSN. In this approach, the fault location is identified by the current measurement of 
the negative sequence components at secondary substation with a medium voltage (MV) distribution feeder. Moreover, M. Majidi et al. [108] proposed an impedance-based fault location technique for fault location identification for DSN. The method can be applied to multi-sources and single-sources of the DSN. In this study, two algorithms are implemented to find the location of faults in the DSN. First, synchronized pre and during-fault voltages are measured by a phasor measurement unit (PMU) and, second, smart meter data is used.

\subsection{Fault Direction Identification}

The power/current flow in MGs is bidirectional due to multi-energy sources and mesh configurations. Directional relaying schemes and algorithms are essential for MG protection to enhance the protection system, reliability, sensitivity, selectivity, and flexibility. Conventional directional relay methods are based on the phasor of voltage and current [125]. Due to the low impedance of the line and feeder of active distribution networks and MGs, it is difficult to identify the fault direction during three-phase faults. The directional relaying scheme is used for the protection of the TL and DSN, including DGs. However, due to the dynamic operating conditions of MGs, the conventional directional relaying technique will not identify the fault direction with high sensitivity and selectivity. However, utilizing adequate directional elements in the protection system for the protection of DSN with a high level of DGs penetration and MGs may enhance the selectivity, security and increase the reliability along with faster operating times.

Fault directional detection is essential to set the overcurrent with increased sensitivity for remote faults. Jones D. et al. [126] discussed the limitations of overcurrent protection without any directional element and the weaknesses of an improperly organized directional element. H. Muda et al. [127] proposed a fault direction identification approach. In this method phase difference between the pre-fault and superimposed sequence components are used to detect the fault direction. Pradhan, A et al. [119] proposed the fault current direction estimated by the positive sequence component of the current during a fault and pre-fault conditions. In addition, Akter S. et al. [128] used the phase angle difference between fault and pre-fault positive-sequence current phasor to estimate the fault direction in a TL. Dehghani, M et al. [78] proposed that fault direction identification based on the phase angle between superimposed voltage and current are applied as fault direction criteria. Jalilian, A et al. [129] proposed that the fault direction computed by the post-fault current. Ali Hooshyar et al. [130] used the direction of the asymmetrical fault is identified by superimposed negative-sequence impedance. Samet, $\mathrm{H}$ et al. [131] presented a directional relaying algorithm. In this method, the current samples for a specific interval of time are multiplied by the pre-fault current and the sign of the power flow in normal condition are used as the fault direction identification index.

Suryanarayana et al. [125] proposed and developed a fault direction identification using the voltage and current signals instead of their phasor values. In this study, the line resistance is computed and its sign is used to identify the fault direction. Moreover, Van Tu et al. [132] used a fault direction detection algorithms based on the positive sequence fault components. The fault direction has been identified using the sign of the fault current component. Karady, G.G et al. [133] use the impedance of the negative sequence current component to determined the fault direction of the fault current. Ashtiani, H.J et al. [134] develop a novel fault directional detection algorithm. In this technique, the fault direction is identified by the sign of the imaginary part of the post-fault current phasor. Hosseini, H.S et al. [135] proposed a directional relay algorithm. The method is based on measurements of the current. The fault direction is estimated with the help of post-fault current components. Furthermore, P. jena at al. [136] proposed a directional relaying algorithm for a series compensated line by applying the positive sequence components. The fault direction identification is based on phase and magnitude change of positive sequence such as current and voltage respectively. Bin Gu et al. [137] proposed a high-speed directional protection for TL. The proposed fault direction identification method is based on the positive sequence of superimposed components. 


\section{Microgrids Protection Strategies}

This section presents different MGs protection strategies. Traditional power system protection and relaying technology have been used for more than a century. However, with continuous development in power system protection research and development, the relay techniques and protection schemes are being upgraded and developed from electromechanical to microprocessor-based to IED along with advanced communication and information technology-based implementation.

Beheshtaein S. et al. [25] presented and discussed different conventional protection techniques such as overcurrent relays (OCR), directional (DOCR), differential protection, distance protection, under/over voltage (UV/OV), and under/over frequency and (UF/OF) protective relays are being utilized for the protection of various power system equipment, such as transmission lines, bus bars, generators, and transformers. The above-mentioned conventional protection techniques, their implementation, and application (including the advantages and limitations) are presented and discussed. However, these conventional protection techniques with some modifications can be used for the protection of MGs. This section presents and discusses different MGs protection methods that are being used or proposed recently in the literature. A summary of different MGs protection techniques with advantages and limitations is provided in Table 4.

\subsection{Impedance and Distance-Based Methods}

Distance relay protection is mostly used for the protection of the transmission lines. The working principle of distance protection is based on the measurements of impedance at the relay point of location. Impedance $(\mathrm{Zm})$ is computed by the measured current $(\mathrm{Im})$ and voltage $(\mathrm{Um})$ at the fundamental frequency on the relay point [138].

$$
\mathrm{Zm}=\frac{U m}{\mathrm{Im}}
$$

Distance relay normally works when the current increase and voltage level decrease are used at high voltage levels. The implementation, application, and characteristics of distance relay are presented [139,140]. W. Huang et al. [141] proposed an impedance-based protection for DSN with DGs. In this method, the impedance is measured by two different approaches. In the first method, the impedance-based differential protection is used as the primary protection that detects a fault condition and provides a reference index for data exchange; the other method is based on low-impedance and is used as backup protection in a coordinated way along with an inverse-time characteristic. Both techniques are independent of MGs operation and are capable to detect and isolate the fault with higher sensitivity. M. Elkhatib et al. [142] presented and discussed an impedance-based protection is for MGs. In this study, the fault detection criteria are based on measuring and monitoring of impedance trajectory at relay point in the feeder. M. Nasir et al. [143] proposed a novel microprocessor-based distance relay or ultra-high voltage transmission line (UHVTL) using symmetrical components.

\subsection{Differential Protection Scheme}

The differential based protection technique is extensively used for the protection of the different power system equipment and systems such as transformers, generators, and MGs. The basic working principle of the differential relaying scheme is to measure and compare the incoming and outgoing current of the test equipment. Under normal operating conditions, the differential current (Id) is zero, which means that the current $I_{1}$ and $I_{2}$ are equal. However, during a fault condition, the difference between the two current $\left(I_{1}\right.$ and $\left.I_{2}\right)$ is greater than zero, this differential current can be used as fault detection criteria. The differential protection scheme is effective, sensitive, selective, and fast [144]. The differential current (Id) can be determined by (3.2)

$$
I_{d}=I_{1}-I_{2}
$$


A differential protection scheme for IIDERs based MGs is proposed for a multi-terminal feeder with multiple IIDGs. In this method, the sum of the current from all terminals are used as fault detection criteria. All of the multiple IIDERs are connected to one single line [145]. Gururani et al. [80] used a differential MGs protection scheme to detect the differential spectral energy as fault detection criteria, whereas the local current measurements are pre-processed by using the S-transform and HHT.

\subsection{Overcurrent (OC) and Directional Overcurrent (DOCR)}

Overcurrent (OC) and directional overcurrent (DOCR) are widely used for power system protection of different components, and OC relay protection is simple and economical. A.H Etemadi et al. [146] proposed an islanded MGs protection based on overcurrent (OC) and overload (OL) protection. The OC and OL protection system is based on terminal voltage measurements of voltage source converter (VSC). The OC protection is used for fault detection, current limitation, and fault clearance by a smooth voltage control restoration mechanism. The OL protection is used to limit the out power of voltage VSC of IIDERs terminal.

Lai, K et al. [12] proposed a Communication-based intelligent protection with a dual set of directional overcurrent relay (DOCR) for an islanded MGs. In this study, the test MGs model is based on IEEE Std. 1547.4. The dual setting DOCR provides coordination between the primary and backup relays. The performance of the proposed protection technique is evaluated by simulating different fault current scenarios such as forward fault, reverse, and normal current on the load side in the transmission line and on the bus side. The impact of the "plug-and-play" characteristics of the system with connection and disconnection DGs and HIF is analyzed for the protection of islanded MGs. The conventional OC protection may cause a longer tripping time or even fail to detect the HIF. K. Oureilidis et al. [147] presented and developed a conventional protection technique for converter-dominated loop MGs by using OC and ESS such as a super-capacitor. The fault detection criteria are proposed by the indirect calculation of impedance at the output of each DERs in a feeder. During a fault condition, the controller of DER adjusts according to the measured impedance by its terminal, and the EESs are set to inject a high current level to the circuit breaker. The injected current is according to the measured impedance that is based on the droop curve characteristics. However, longer tripping time of the OC, cost, and size of EES are the main limitations of this method.

Costa, F.B et al. [148] proposed an OC relay protection system for the DSN with DGs integration. This method is based on a WT and OC relay. The boundary scaling coefficient energy for the fault currents is used for fault detection criteria.

\subsection{Sequence/Symmetrical Component-Based Methods}

Fault detection and location for MGs with grid-connected with the capability of low voltage ride-through (LVRT) have been proposed [31]. The fault detection and location are identified using a sequence component such as the positive sequence of the fault current and phase angle difference among the positive sequence bus voltages. Low and HIF fault is detected by applying this technique. H. Laaksonen et al. [149] develop a method for HIF detection in MGs for various grounding practices. In this method, zero sequence and negative sequence fault current components are used. This method effectively detects HIF and various fault locations and types, including the impedance. Furthermore, L. Jing et al. [18] developed a MGs protection scheme based on interface protection and unit protection. Firstly, as interface protection in this method the zero sequence component such as voltage and the current angle at the interconnection transformer of a faulty feeder to detect and identify a fault condition. Secondly, as unit protection, the method is established by the assessment of the zero-sequence current and its phase direction at every single the interconnection point of the DERs and load. 


\subsection{Adaptive Protection Techniques}

Adaptive protection is a promising solution for MGs, as it adaptively updates its settings according to the variations and dynamics of the MGs. The purpose and aim of an adaptive protection scheme have to update the setting of protective devices, such as Intelligent Electronic Device (IED), according to the state changes of the active distribution grid [150]. Recently, widespread research has been carried out in this field. The adaptive protection for the MGs system using a digital relay in conjunction with an advanced communication system is presented in [28]. D. Ishchenko et al. [40] proposed an adaptive protection scheme for DSN using IED and IEC-61850 is based communication

E.A Mohamed et al. [151] developed and implemented of advanced control and adaptive protection functionality for medium voltage MGs. In this method, the real-time data exchange mechanisms based on IEC 61850 Std data objects and characteristics are used to implement the controller function of the MGs. Figure 7 illustrates an example of the adaptive protection scheme for a grid-connected MGs. The system consists of two DGs and a synchronous generator. Protective devices like IEDs and circuit breakers as used to detect and isolate a fault. Moreover, a COM 600-based protection-control unit and the communication system network are used to monitor the system status and configure the relay settings.

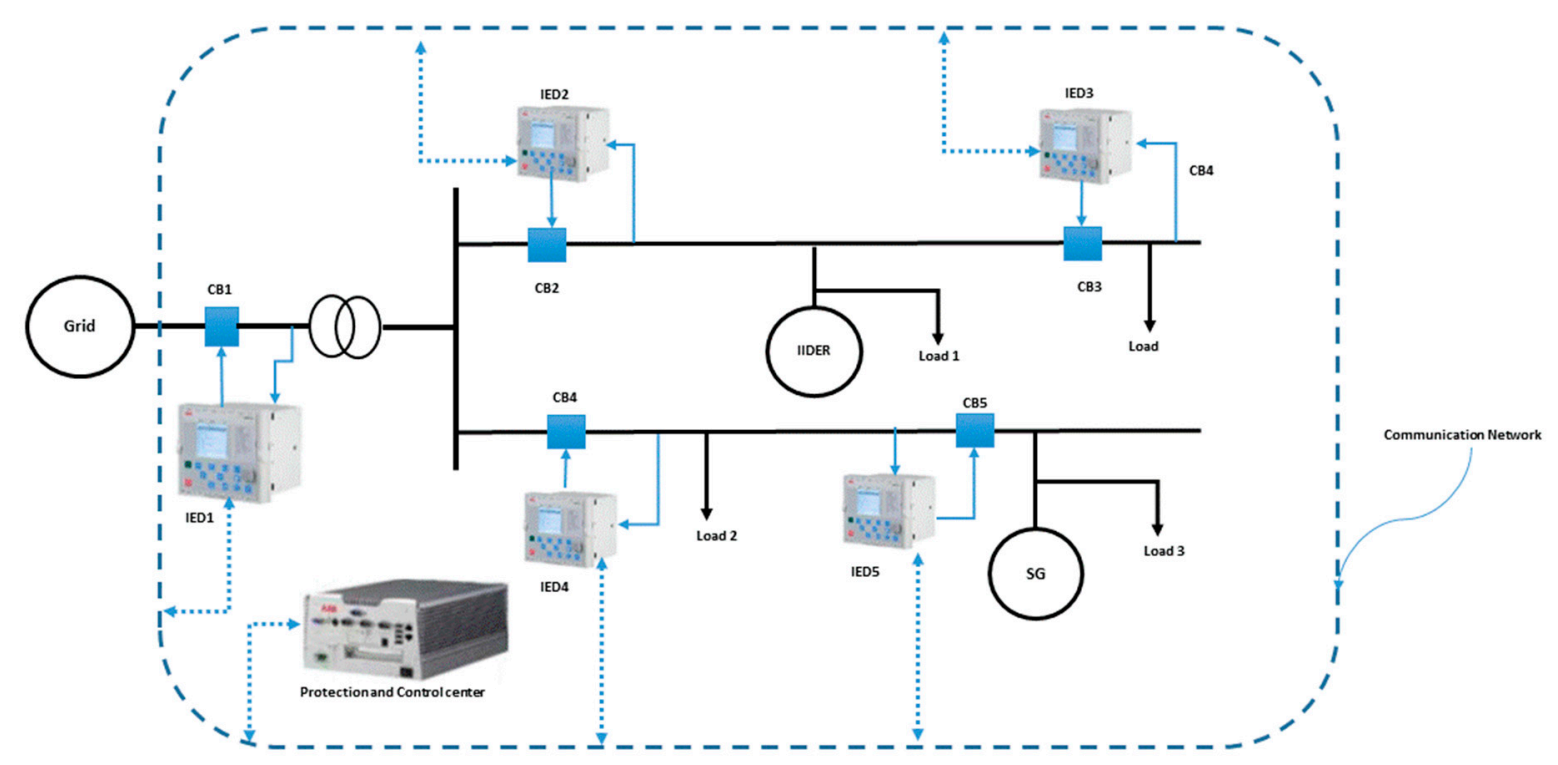

Figure 7. A typical example of an adaptive protection system.

Adaptive protection in conjunction with a control system for a MG system is designed and implemented at "Haiuoto Island Finland." The protection system is implemented with the help of IEDs and IEC 60870-5-104 and IEC-61850. The centralized controller analyzes the real-time data received by each IED. The IEC 61131-3 compatible language implements the control and monitoring algorithms [28]. H. Lin et al. [138] proposed an adaptive distance protection with a phasor measurement unit (PMU) function. W. Zhao et al. [150] presented and proposed a closed-loop simulation for a centralized and coordinated adaptive protection. The proposed adaptive protection system was implemented in RT-LAB. The model consists of a central master controller (COM 600). The function of COM 600 is to monitor and update the group setting in real-time according to system variations. IEC-61850 based communication network is used for data exchange between COM 600 and IED. Moreover, the hardware-in-the-loop (HIL) setup is implemented using an RT-Lab, a feeder protection relay, soft IEDS, an amplifier, and an I/O card and COM 600 central controller.

An adaptive overcurrent relaying (AOCR) protection technique is developed and proposed for MGs protection for grid-connected and islanded modes. The proposed AOCR operation is based on a moving average line load estimation, the DER status, and adapt the pickup current according 
to the system operating conditions. The proposed method is independent on any other external control system to set the relay pickup setting to confirm considerably a low communication system overhead [152]. H.Lin et al. [35] developed an adaptive protection scheme with ML for MGs. The Pearson correlation coefficient approach is implemented to analyze the uncertain elements in MGs quantitatively. Next, ANN with the SVM-based model is utilized to identify state recognition in MGs. By using the state recognition algorithm, the adaptive reconfigurations could be helpful for the decision making for the updating the protection scheme parameters and settings according to the MGs system changes to confirm the consistency of the proposed adaptive protection. Sharma, A et al. [153] presented a metaheuristic optimization-based algorithm and developed to identify the optimum setting for a DOCR. Jones, D et al. [126] used an adaptive DOCR relaying technique using positive sequence and negative sequences superimposed current components for fault detection. P. Mahat, et al. [154] developed and design a novel adaptive overcurrent protection. In this study, the protective relay settings are adjusted according to the changes in the system operating condition and configuration.

A centralized protection scheme for MGs is proposed by utilizing the Microgrids protection controller (MPC). The function of the MPC is to process the received data from PMUs. This method was based on a positive sequence of complex power. The PMUs extract and communicate the fault data from each end of the line to the MPC. The received fault data are processed by MPC for identifying the fault, its location as well as for fault isolation [155]. H. Lin et al. [156] presented an adaptive directional overcurrent (ADOC) protection with independent state estimation of the relays for MGs. D. Ishchenko et al. [40] developed an adaptive protection scheme based on IED and IEC-61850 Std. communication for DSN with a large number of DERs. In this protection scheme, a centralized controller is used to analyze the received data from IED to update the protection devices for intelligent and fast fault detection and isolation. D.S, Kumar et al. [157] proposed an ADOCR for the protection of meshed DSN. The proposed ADOCR based on a hybrid optimization framework that continuously monitors and detects system uncertainties such as fault events. The ADOCR numerical relay has a two-phase approach to set the relay settings. The proposed approach is an adaptive fuzzy current detecting the module that was used to determine the optimal current setting according to the output power and terminal voltage. Then, an optimization algorithm is applied to set the coordination time for an optimum operating time of ADOCR.

\subsection{Communication-Assisted Protection Techniques}

The communications network system is being used for the control, monitoring, energy management including the protection of MGs for their reliable and efficient utilization in a coordinated way. The operating characteristics continuously altered mainly by the switching of the operation mode such as grid and islanded mode, varying number DGs, connection and disconnection of load, consequently caused the level fault current variation. However, the communication network system is useful for the MGs protection system and PDs to dynamically update the settings in real-time and change the tripping characteristics [33]. The communication network is implemented to monitor and change the relay setting accordingly to the dynamic characteristics of the MGs system configuration [32]. A communication- assisted protection method for islanded MGs is applied to update and set the protective relay settings according to the system dynamics and configuration [40]. The IEC-61850 and IEC-61850-7-420 based communication standards provide information modeling and data modeling for the MGs protection system [149,158]. Communication systems based on IEC-61850 are being used for fast, reliable and selective operation of the relay for future LV MGs protection systems [26]. W. Zhao et al. [150] used an IEC-61850 based communication network for data exchange between COM 600 and IEDs for MGs protection. The IEEE 802.16/WiMAX network is utilized to implement protection strategies for MGs in $[33,159]$ respectively. However, the communication system, speed, efficiency, data loss, data delay, and failure are key issues that affect the protection system reliability.

Cintuglu et al. [158] proposed an agent-based distributed communication assisted protection scheme for islanded MGs. The proposed method is used to solve two problems, such as overcurrent 
and frequency selectivity. In the first case, overcurrent selectivity is established on the characteristics of the feeder along with the position of IEDs. Next, the frequency selectivity problem is resolved by an adaptive approach to avoid pulse load effects in islanded MGs. IEC-61850 framework and GOOSE protocol-messaging use the communication system for the proposed approach. In [32], the authors proposed and developed a new protection scheme for MGs based on the MGs control and protection unit (MCPU). The IEC-61850 and IEC 61850-7-420 Std used for communication between the MCPU and PDs to monitor the entities within the MGs system and updates the control and protection setting according to the operating condition including the fault event.

W. Huang et al. [41] presented an adaptive MGs operation based on IEC-61850 and IEDs for the "plug and play" operation. The IEC-61850 has provided the information modeling, standardized data exchange, and data modeling for MGs network operation and its mode conversion. Real-time information and data exchange by utilizing IEC-61850 can be used for "plug and play" integration of the MGs components, automatic control, protection, and monitoring.

A hybrid protection scheme for MGs is based on the differential inclusion with an adaptive protection method that has been proposed [33]. In this study, the protection system changes its setting by using a switching algorithm to change the protection module by a differential scheme or to adaptive protection. The hybrid protection system is implemented by using the IEEE 802.16/WiMAX network. Nikolaidis et al. [160] implemented a communication-based protection scheme is proposed to implement the DOCR that assists by interrupting and blocking transfer functions. Casagrande et al. [20] used a data mining approach for a communication-assisted based protection technique for MGs to detect the relay setting and parameters. Fault detection and communication between protective relays are based on optimal electrical feature selection. Recently, Eissa, $\mathrm{M}$ et al. [159] developed an "Internet of Energy" (IoE)-based novel protection method for the smart grids environment. This approach is denoted as "i-protection" for smart grids. In this study, the IEEE-802.16 based WiMAX technology has been used to implement the i-protection scheme. The IEDs are used to monitor the system and detect any fault condition in the IoE-based protection system.

\subsection{Protection of Multi Microgrids}

Multi-microgrids (MMGs) or microgrids clusters (MGCs) are a group of interconnected AC, DC, and Hybrid AC/DC MG configurations. However, MGCs and MMGs are interconnected systems with several ACs, including the DC-based MGs system. The MMGs supports mutual power transfer among MGs and increases the utilization of RESs [161]. MMGs provide better solutions for the power supply, reliability, and flexibility [162]. Bullich-Massagué et al. [8] discussed and presented the possible MMGs architectures and their benefits. Furthermore, Y. Khayat et al. [163] presented the MGs cluster structures, such as static and dynamic topologies with smart static switches. Zhou, $X$ et al. [161] developed and proposed different architectures of MMGs system including their autonomous coordinated control strategy. However, various challenges in control, energy management, and protection are still need to be investigated for the reliable operation of MMGs and MGCs systems.

A control scheme of MMGs converter is proposed and implemented to manage the MMGs for optimal operation, islanding and fault condition [162,164]. N. Bazmohammadi et al. [165], proposed a hierarchical stochastic energy management technique for MMGs. Zhang et al. [162] proposed a protection technique for internal faults. In this method, the fault detection criterion is based on the measurement of changes in both the phase difference and admittance, respectively. 
Table 4. Protection schemes for Microgrids.

\begin{tabular}{|c|c|c|c|}
\hline Protection Technique & Features & Advantages & Limitations \\
\hline Overcurrent [147] & $\begin{array}{l}\text { - High current is injected by ESS, } \\
\text { proportionally to the measured } \\
\text { impedance on the line }\end{array}$ & $\begin{array}{ll}\text { - } & \text { Without any } \\
\text { - } & \text { Communications system. } \\
\text { - } & \text { Coordinated with the same } \\
\text { current level of OCR }\end{array}$ & $\begin{array}{l}\text { - Only for islanded MGs. } \\
\text { - } \quad \text { Longer tripping time for } \\
\text { some cases } \\
\text { - Cost and size of EES }\end{array}$ \\
\hline $\begin{array}{c}\text { WT overcurrent relay } \\
{[148]}\end{array}$ & $\begin{array}{l}\text { - } \quad \text { Boundary scaling } \\
\text { coefficient energy }\end{array}$ & $\begin{array}{ll}\text { - } & \text { fast and simple } \\
\text { - } & \text { HIF detection } \\
\text { - } & \text { computational burden is low }\end{array}$ & $\begin{array}{l}\text { - Fault location and } \\
\text { classification are not given }\end{array}$ \\
\hline $\begin{array}{l}\text { Overcurrent and } \\
\text { overload [146] }\end{array}$ & $\begin{array}{l}\text { - Based on } \\
\text { voltage measurements } \\
\text { The fault is detected by OC } \\
\text { and OL is used to limit the } \\
\text { output power }\end{array}$ & 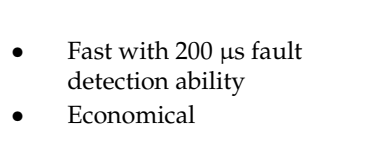 & $\begin{array}{l}\text { - Classification of faults and } \\
\text { HIF are not considered } \\
\text { Only applied for } \\
\text { Islanded operation }\end{array}$ \\
\hline $\begin{array}{l}\text { Adaptive directional } \\
\text { overcurrent [157] }\end{array}$ & $\begin{array}{l}\text { - } \quad \text { Adaptive-fuzzy-based } \\
\text { - Optimization algorithm }\end{array}$ & $\begin{array}{ll}\text { - } & \text { Adaptive } \\
\text { - } & \text { Coordinated } \\
\text { - } & \text { Efficient }\end{array}$ & $\begin{array}{ll}\text { - } & \text { Learning-based } \\
\text { - } & \text { Complex } \\
\text { - } & \text { Costly }\end{array}$ \\
\hline $\begin{array}{c}\text { Adaptive protection } \\
\text { [152] }\end{array}$ & $\begin{array}{l}\text { - } \\
\text { - } \quad \text { Communtive overcurrent } \\
\text { coordination }\end{array}$ & $\begin{array}{l}\text { - } \\
\text { - } \quad \text { Coordination for two-mode } \\
\text { MGs operation. }\end{array}$ & $\begin{array}{l}\text { - } \quad \text { HIF and fault classification } \\
\text { not considered } \\
\text { - } \quad \text { Complex }\end{array}$ \\
\hline $\begin{array}{l}\text { central protection unit } \\
\text { [32] }\end{array}$ & $\begin{array}{l}\text { - Centralized protection system } \\
\text { with communications } \\
\text { - Dynamically calculates } \\
\text { fault currents }\end{array}$ & $\begin{array}{l}\text { - } \\
\text { - } \quad \text { Fastaptive in nature } \\
\end{array}$ & $\begin{array}{l}\text { - } \quad \text { Communication failure } \\
\text { - } \quad \text { HIF and Fault classification }\end{array}$ \\
\hline $\begin{array}{l}\text { Hybrid adaptive and } \\
\text { differential [33] }\end{array}$ & $\begin{array}{l}\text { - } \\
\text { - } \quad \text { Differential protection } \\
\text { - Communications assisted } \\
\text { switching algorithm to shift } \\
\text { from one another scheme }\end{array}$ & $\begin{array}{l}\text { - Adaptively detect setting for } \\
\text { a different mode of operation } \\
\text { - Fast and accurate }\end{array}$ & $\begin{array}{l}\text { - Communication-failure } \\
\text { - Costly }\end{array}$ \\
\hline $\begin{array}{l}\text { Differential sequence } \\
\text { component [145] }\end{array}$ & $\begin{array}{ll}\text { - } & \text { Differential protection } \\
\text { - } & \text { Symmetrical components } \\
\text { - } & \text { Current magnitudes } \\
\text { - } & \text { Current THD and phase angles }\end{array}$ & - $\quad$ fast & $\begin{array}{l}\text { - } \quad \text { Many features } \\
\text { - } \quad \text { Costly } \\
\text { - } \text { Communication failure }\end{array}$ \\
\hline Agent-based [158] & $\begin{array}{ll}\text { - } & \text { overcurrent selectivity } \\
\text { - } & \text { adaptive frequency-selectivity } \\
\text { - } & \text { (IEDs) IEC61850 } \\
\text { - } & \text { GOOSE protocol }\end{array}$ & $\begin{array}{ll}- & \text { Fast } \\
\text { - } & \text { Intelligent }\end{array}$ & $\begin{array}{l}\text { - } \quad \text { for islanded MGs. } \\
\text { - } \text { HIF and fault classification } \\
\text { not given } \\
\text { - Costly } \\
\text { - Complex }\end{array}$ \\
\hline
\end{tabular}

\section{The Protection Coordination Technique}

Protection coordination is essential for a reliable protection system. Normally, the objective of the overcurrent relay protection coordination is to identify as the closet relay to the faulty section. Next, the corresponding relay and circuit breaker (CB) operates to detect and clear the fault. The coordination between the primary and backup OCR can be adjusted time setting multiplier (TDM) and plug setting multiplier (PMS) to achieve an optimal setting of the time delay. The defined time delay between the primary and back relays is known as the coordination time interval (CTI). The appropriate value of CTI is mandatory between the primary and backup relay, that both relays function in a coordinated way [12]. Protection coordination of MGs is complex and non-linear due to its dynamic operation characteristics. Recently, different optimization algorithm $(\mathrm{OA})$ and formulations are being utilized for the optimal coordination setting of both the primary and backup relay, and solve the protection coordination problem (PCP). Moreover, in different research works, the PCP of a MGs system is formulated by linear programming (LP), non-linear programming (NLP), and mixed-integer non-linear 
programming (MNLP). Moreover, the PCP problem is solved by implementing OA such as GA, PSO, Ant-Colony Optimization (ACO), and Cuckoo Algorithm (COA) [43,166-168].

Yazdanpanahi et al. [169] investigated the PCP of IIDGs-based MGs for the coordination of fuse-recloser. A control scheme is designed for the IIDGs controller, whose objective is to reduce the output fault current that impacts the coordination of fuse-recloser. The controller limits and adjust the fault current according to the terminal voltage. If a deeper voltage sag is observed, then the IIDGs controller injects a low level of the current. A hybrid optimization approach, like GA and PSO, solves the PCP of the DOCR [44]. A.I Atteya et al. [166] presented the NLP and modified particle swarm optimization (MPSO) OA used to formulate and solve the relay coordination problem for an adaptive protection system respectively.

A centralized protection unit scheme is proposed for MGs protection [170]. A microgrids central protection unit (MCPU) is used to set up a communication channel between the protective relay and DG in the MGs system. Two different parameters are used for protection and coordination. Firstly, the fault current coefficient is determined for each DGs fault current at a single point in the MGs. Secondly, the optimal setting of the relay determined for the selective and coordinated operation of the protection relay. M. Alam et al. [171] develop and proposed an adaptive PCP for the numerical directional overcurrent relays (DOCR) is solved by applying a mathematical programming language, and this OA is based on the interior point optimization solver. Different operating conditions are considered, such as disconnection of the loads, generators, and lines. Shih et al. [168] proposed an adaptive DOCR. In this study, the PCP of the proposed adaptive DOCR is formulated as NLP, and it is solved by ant-colony OA.

El-Naily et al. [172] used a coordination approach for an OC relay is solved by a constraint and non-standard characteristics for the MGs protection scheme. Zamani et al. [173] developed and proposed a novel microprocessor-based relay for protection and coordination of a low inertia MGs system. The proposed relay is capable to detect fault current variation along with the changes in the mode of operation of MGs in a coordinated way. H.M. Sharaf et al. [42] investigated a protection scheme for MGs with the DOCR by multiple settings with the help of a communication system, that is used to determine the optimal protection coordination. In this study, PCP is formulated as NLP to set the CTI between the primary as well as the backup relay. Dehghanpour et al. [167] use to solve the PCP by using LN and cuckoo algorithm (COA) for the DOCRs. The hybrid COA-LP-OA is applied to minimize the CTI as well as determine the optimal value for a fault current limiter (FCL) at the PCC. The obtained results are analyzed and compared with GA and PSO. Waleed et al. [43] formulated the optimal setting of OCR and the FCL size as an NLP-based problem. Next, the GA is used to solve the PCP. The method is applied to a mesh configuration of DSN with the DERs. The FCL size and the OCR setting are determined for grid-connected mode and islanded mode of MGs operation. E.A. Mohamed et al. [151] proposed a digital protection coordination technique for islanded MGs for its load frequency control, including an over/under frequency protective relay (OUFR). The proposed digital OUFR works in both conditions, such as over and under frequency in a coordinated way with the help of a PID controller.

B. Fani et al. [174] developed two different approach to solve the PCP of a DSN with the PV system. In the first method, the protection coordination characteristics curve is modified accordingly with the PV system penetration level, and in the second approach, the out current level of the PV inverter is limited accordingly with the penetration level. Dahej, A.E et al. [175] proposed a solid-state unidirectional fault current limiter (SSUFCL) to limit the MGs contribution to the grid side faults and to enhance the power quality margins along with protection coordination. Moreover, if a fault detected inside of the MGs system, the SSUFCL must be disabled. The setting of the OCR and SSUFCL characteristics are determined for the optimal protection coordination.

$\mathrm{He}, \mathrm{H}$ et al. [176] proposed a superconducting fault current limiter (FCL) and implemented to resolve the protection coordination along with the FRT capability. H. Saberi et al. [177] use the optimal setting of DOCRs for a meshed DSN. In this study, the PCP of the DOCR is formulated and solved by the 
MINLP and generalized benders decomposition (GBD) techniques, respectively. Albasri, F.A et al. [178] solved the PCP of the DOCRs by formulating the LP and population-based evolutionary algorithm such as biogeography-based optimization (BBO) and hybrid BBO. The increased penetration of DGs in future grid results in non-selective protection action. The relay setting needs to change for every single DG installation in the system, and the protection coordination must be guaranteed. L. Huchel et al. [179] proposed a novel method to identify a single relay setting approach for possible future DGs planning. In this study, LP and simplex OA are implemented to formulate and solve the PCP. Furthermore, the application of FCL is investigated for planned DG capacities. It is observed that the protection setting does not need to be changed if the penetration level of DG is varying and protection coordination will be preserved if any DG is out of service. D. S. Alkaran et al. [180] implemented a fuzzy-GA-based approach to solve the PCP and operating time for the OC relay of the interconnected network.

K.A Saleh et al. [181] proposed the PCP of DOCR by considering the N-1 contingency, such as a single outage of a line, DGs, substation, and the two-mode of MGs operation. The MINLP is applied to formulate the PCP with a different set of coordination constraints used for the line, substation, and DG outages, including the MGs operation mode. Recently, Ojaghi, M et al. [182] used the adaptive protection coordination technique for the OCR. The LP method is applied for the optimal coordination of OCRs. A clustering technique is used to classify and reduce the setting group of the potential operating configuration of the network. The advantage of this method is that the number of clusters is selected with an equal number of OCRs setting groups. For each topology cluster, a clustering index is defined and the setting of OCR is determined by a coordination method. Furthermore, T.S Aghdam et al. [183] proposed a novel variable tripping time technique (VTTT) for a multi-agent differential protection technique for grid-connected and islanded MG system operations. This approach is utilized for coordination with lateral fuse and protective relay. A.M. Tsimtsios et al. [184] proposed and developed a communication-assisted multifunctional relay with "plug-and-play" characteristics for the protection of a meshed DSN with DGs. The advantages of this novel method are that it can be applied for all operating conditions, independent of any specific system configuration, and provides optimal coordination.

\section{Research Challenges and Future Directions}

During a fault condition, MGs show a more complex and dynamic behavior due to the involvement of bidirectional power flow and power-electronics-based inverter interface-distributed energy resources with varying capabilities of short circuit current contribution. Among different challenges, one of the most serious is the fault detection and protection of MGs. Fault detection and protection in MGs is a complex issue due to the varying and bidirectional nature of fault currents, different types, and location of the DGs. Therefore, a reliable and fast fault detection and protection scheme is desirable for MGs, which can prevent the system from collapsing. Considering this issue, various challenges and future directions/trends and their limitation are summarized as follows:

- Modification of Conventional Protection Techniques: Traditional protection schemes like, differential, directional overcurrent, and distance-based protection can be used for the protection of the MGs systems with appropriate modifications and upgradations. Such modifications could be achieved by changing the fault detection criteria, such as fault detection based on signal processing. To this end, AI and ML-based techniques can provide promising solutions. The modified conventional schemes are mostly simple and could be implemented with or without a communication system. However, reliability, selectivity, speed, and cost need to be considered.

- Modified Control Scheme: The MG system is mainly interfaced with converter/inverter to the loads or the main grid. The control response can be designed faster by designing at a higher bandwidth. In addition, different control technologies can be employed to achieve the reliable operation of the MGs. Limited fault current contribution of inverter/converter needed to be considered for a reliable protection system design. Hence, changing the type, size, and control technology of converters need to be considered in the design and for better performance. 
- Using Fault Current Limiters: Fault current limiters are being used to limit the fault current from DG or the utility grid in order to minimize the fault current contribution and achieve selective coordination among protection devices. However, the type and size of FCL is a challenging task to design. Further, the extra cost of such devices will increase the overall cost of the protection system.

- Using Energy Storage: Energy storage systems such as the batteries, flywheels, and superconducting energy storage can be used in the MG protection system, both to feed the fault a high level of current and as inertia supports during faults.

- Adaptive Protection: Adaptive protection with an advanced communication system is being used and implemented for the protection of MGs. This protection system is a prominent solution for MG system protection, as the protection devices such as IEDs setting can be updated automatically according to the system changes. Moreover, limitations such as communication failures and faults/attacks in the cyber-layer need to be addressed more comprehensively in the adaptive protection schemes.

- IoT-Based MGs Protection: Internet of Thing (IoT) is a new technology that is being used in this sector for energy management and the operation of AC and DC MGs. IoT-based protection systems can be used and implemented as IoT is provided by advanced communications, but cyber-layer faults/attacks can propose new challenges.

- Island Detection/Protection: Island detection is important to isolate the MG systems from the utility grid in case of the fault on-grid side. In multi-MG systems, islanding detection can be used to detect the faults in any MG in the cluster.

- Protection during Power Swings: A massive number of wind turbines are being integrated into distribution systems worldwide. They may impact power swing protection of the distribution system. This area needs to be considered for a reliable protection design. If a fault occurs during a power swing, which can occur among the grid-forming converters in a MG, it can lead to the malfunction of the protective relays and needs to investigate more.

- Multi MGs Protection: Multi-microgrids (MMGs) are a collection of interconnected hybrid AC/DC and AC, and DC MGs. This provides reliable and continuous power to the consumer and power share among MGs. However, their control, energy management, and protection are complex. Multi MGs protection is a new research area that needs to be investigate further. The role of interlinking devices can directly determine which protection scheme is more reliable and appropriate.

\section{Conclusions}

The protection of MGs plays an important role in uninterruptable and reliable operation. Increased penetration of DGs shows that the conventional protection schemes of the DSN are not reliable enough. The DGs uncertainties and continuous variation result in varying fault currents. Due to the operating conditions and dynamic characteristics of the MGs system, the protection and coordination scheme needs to be designed accordingly. This paper provides a review of recent advances in AC MG fault study and protection, including protection coordination methods. Moreover, various fault detection, classification, localization, and fault direction identification schemes are categorized based on the employed techniques along with their advantages and limitations. The literature review shows that AC MG fault detection and classification, including its direction for protection and coordination, are primarily based on different digital signal processing and artificial intelligence methods. However, the computational complexity and training sets of AI-ML-based techniques need to be considered for increased efficiency and reliability of the protection system. This review also highlights that, by using advanced communication and measurement techniques, the MG protection system can be designed adaptively for adjusting and automatically updating the relay settings. Furthermore, different techniques and approaches are reviewed to minimize the impact of increased integration of DGs in DSN for its protection and coordination. Dynamic operational characteristics of the MGs system need a flexible protection method that may divide the system in the various zone or clusters based on the clustering indices technique. 
Author Contributions: Conceptualization, N.H. and J.M.G.; methodology, N.H., J.M.G. and M.N.; formal analysis, N.H.; investigation, N.H.; resources, N.H. and J.C.V.; writing-original draft preparation, N.H.; writing-review and editing, M.N., J.M.G., J.C. Vasquez.; visualization, N.H.; supervision, J.M.G., J.C.V. and M.N.; project administration, J.M.G.; funding acquisition, J.M.G. All authors have read and agreed to the published version of the manuscript.

Funding: This work was funded by a "Villum Investigator grant" (no. 25920) from The Villum Fonden, Denmark and Balochistan University of Engineering and Technology Khuzdar, Pakistan.

Acknowledgments: The authors acknowledge the cooperation and contribution of Department of Energy Technology Alborg University Denmark and Balochistan University of Engineering and Technology Khuzdar Pakistan.

Conflicts of Interest: The authors declare no conflict of interest.

\section{References}

1. Ton, D.T.; Smith, M.A. The US department of energy's microgrid initiative. Electr. J. 2012, 25, 84-94. [CrossRef]

2. Anonymous. IEEE Standard for the Specification of Microgrid Controllers. Transm. Distrib. IEEE Power Energy Soc. 2018, 1-43.

3. Hossain, M.A.; Pota, H.R.; Issa, W.; Hossain, M.J. Overview of AC microgrid controls with inverter-interfaced generations. Energies 2017, 10, 1300. [CrossRef]

4. Hossain, M.A.; Pota, H.R.; Hossain, M.J.; Blaabjerg, F. Evolution of microgrids with converter-interfaced generations: Challenges and opportunities. Int. J. Electr. Power Energy Syst. 2019, 109, 160-186. [CrossRef]

5. Guerrero, J.M.; Chandorkar, M.; Lee, T.; Loh, P.C. Advanced control architectures for intelligent microgrids-Part I: Decentralized and hierarchical control. IEEE Trans. Ind. Electron. 2012, 60, 1254-1262. [CrossRef]

6. Vasquez, J.C.; Guerrero, J.M.; Miret, J.; Castilla, M.; De Vicuna, L.G. Hierarchical control of intelligent microgrids. IEEE Ind. Electron. Mag. 2010, 4, 23-29. [CrossRef]

7. Parhizi, S.; Lotfi, H.; Khodaei, A.; Bahramirad, S. State of the art in research on microgrids: A review. IEEE Access 2015, 3, 890-925. [CrossRef]

8. Bullich-Massagué, E.; Díaz-González, F.; Aragüés-Peñalba, M.; Girbau-Llistuella, F.; Olivella-Rosell, P.; Sumper, A. Microgrid clustering architectures. Appl. Energy 2018, 212, 340-361. [CrossRef]

9. Zia, M.F.; Elbouchikhi, E.; Benbouzid, M. Microgrids energy management systems: A critical review on methods, solutions, and prospects. Appl. Energy 2018, 222, 1033-1055. [CrossRef]

10. Abdel-Galil, T.K.; Abu-Elanien, A.E.; El-Saadany, E.; Girgis, A.; Mohamed, Y.A.; Salama, M.; Zeineldin, H. Protection Coordination Planning with Distributed Generation; Final Report - CETC-Varennes 2007-149 (TR) June 2007; Qualsys Engco.Inc.: Waterloo, Canada, 2007.

11. Teimourzadeh, S.; Aminifar, F.; Davarpanah, M.; Guerrero, J.M. Macro protections for micro grids. Toward a New Protection Paradigm Subsequent to Distributed Energy Resource Integration. IEEE Ind. Electron. Mag. 2016, 10, 6-18. [CrossRef]

12. Lai, K.; Illindala, M.S.; Haj-ahmed, M.A. Comprehensive protection strategy for an islanded microgrid using intelligent relays. In Proceedings of the 2015 IEEE Industry Applications Society Annual Meeting, Addison, TX, USA, 18-22 October 2015; pp. 1-11.

13. Baran, M.E.; El-Markaby, I. Fault analysis on distribution feeders with distributed generators. IEEE Trans. Power Syst. 2005, 20, 1757-1764. [CrossRef]

14. Loix, T.; Wijnhoven, T.; Deconinck, G. Protection of microgrids with a high penetration of inverter-coupled energy sources. In Proceedings of the 2009 CIGRE/IEEE PES Joint Symposium Integration of Wide-Scale Renewable Resources into the Power Delivery System, Calgary, AB, Canada, 29-31 July 2009; pp. 1-6.

15. Nikkhajoei, H.; Lasseter, R.H. Microgrid protection. In Proceedings of the 2007 IEEE Power Engineering Society General Meeting, Tampa, FL, USA, 24-28 June 2007; pp. 1-6.

16. Turcotte, D.; Katiraei, F. Fault contribution of grid-connected inverters. In Proceedings of the 2009 IEEE Electrical Power \& Energy Conference (EPEC), Montreal, QC, Canada, 22-23 October 2009; pp. 1-5.

17. Zamani, M.A.; Yazdani, A.; Sidhu, T.S. A control strategy for enhanced operation of inverter-based microgrids under transient disturbances and network faults. IEEE Trans. Power Deliv. 2012, 27, 1737-1747. [CrossRef] 
18. Jing, L.; Son, D.; Kang, S.; Nam, S. A novel protection method for single line-to-ground faults in ungrounded low-inertia microgrids. Energies 2016, 9, 459. [CrossRef]

19. Sadeghkhani, I.; Golshan, M.E.H.; Mehrizi-Sani, A.; Guerrero, J.M.; Ketabi, A. Transient monitoring function-based fault detection for inverter-interfaced microgrids. IEEE Trans. Smart Grid 2016, 9, 2097-2107. [CrossRef]

20. Casagrande, E.; Woon, W.L.; Zeineldin, H.H.; Kan'an, N.H. Data mining approach to fault detection for isolated inverter-based microgrids. IET Gener. Transm. Distrib. 2013, 7, 745-754. [CrossRef]

21. Telukunta, V.; Pradhan, J.; Agrawal, A.; Singh, M.; Srivani, S.G. Protection challenges under bulk penetration of renewable energy resources in power systems: A review. CSEE J. Power Energy Syst. 2017, 3, 365-379. [CrossRef]

22. Coster, E.; Myrzik, J.; Kling, W. Effect of DG on distribution grid protection. Distributed Generation. Gaonkar, D.N., Ed.; Available online: https://www.intechopen.com/books/distributed-generation/effect-ofdg-on-distribution-grid-protection (accessed on 30 April 2020).

23. Antonova, G.; Nardi, M.; Scott, A.; Pesin, M. Distributed generation and its impact on power grids and microgrids protection. In Proceedings of the 2012 65th Annual Conference for Protective Relay Engineers, College Station, TX, USA, 2-5 April 2012; pp. 152-161.

24. Bak-Jensen, B.; Browne, M.; Calone, R.; González, R.C.; Craib, A.; Donnart, G.; Dumitrascu, D.; Engel, M.; Hanuš, R.; Hoidalen, H. Protection of Distribution Systems with Distributed Energy Resources; CIGRE: Paris, France, 2015.

25. Beheshtaein, S.; Cuzner, R.; Savaghebi, M.; Guerrero, J.M. Review on microgrids protection. IET Gener. Transm. Distrib. 2019, 13, 743-759. [CrossRef]

26. Laaksonen, H.J. Protection principles for future microgrids. IEEE Trans. Power Electron. 2010, 25, $2910-2918$. [CrossRef]

27. Voima, S.; Laaksonen, H.; Kauhaniemi, K. Adaptive protection scheme for smart grids. In Proceedings of the 12th International Conference on Developments in Power System Protection · DPSP, Copenhagen, Denmark, 31 March-3 April 2014.

28. Laaksonen, H.; Ishchenko, D.; Oudalov, A. Adaptive protection and microgrid control design for Hailuoto Island. IEEE Trans. Smart Grid 2014, 5, 1486-1493. [CrossRef]

29. Singh, M.; Basak, P. Adaptive protection methodology in microgrid for fault location and nature detection using q0 components of fault current. IET Gener. Transm. Distrib. 2018, 13, 760-769. [CrossRef]

30. Gao, Z.; Cecati, C.; Ding, S.X. A survey of fault diagnosis and fault-tolerant techniques-Part I: Fault diagnosis with model-based and signal-based approaches. IEEE Trans. Ind. Electron. 2015, 62, 3757-3767. [CrossRef]

31. Zhang, F.; Mu, L. A Fault Detection Method of Microgrids with Grid-Connected Inverter Interfaced Distributed Generators Based on the PQ Control Strategy. IEEE Trans. Smart Grid 2018, 5, 4816-4826. [CrossRef]

32. Ustun, T.S.; Ozansoy, C.; Zayegh, A. Modeling of a centralized microgrid protection system and distributed energy resources according to IEC 61850-7-420. IEEE Trans. Power Syst. 2012, 27, 1560-1567. [CrossRef]

33. Ustun, T.S.; Khan, R.H. Multiterminal hybrid protection of microgrids over wireless communications network. IEEE Trans. Smart Grid 2015, 6, 2493-2500. [CrossRef]

34. Mishra, D.P.; Samantaray, S.R.; Joos, G. A combined wavelet and data-mining based intelligent protection scheme for microgrid. IEEE Trans. Smart Grid 2015, 7, 2295-2304. [CrossRef]

35. Lin, H.; Sun, K.; Tan, Z.; Liu, C.; Guerrero, J.M.; Vasquez, J.C. Adaptive protection combined with machine learning for microgrids. IET Gener. Transm. Distrib. 2019, 13, 770-779. [CrossRef]

36. Abdelgayed, T.S.; Morsi, W.G.; Sidhu, T.S. Fault detection and classification based on co-training of semisupervised machine learning. IEEE Trans. Ind. Electron. 2017, 65, 1595-1605. [CrossRef]

37. James, J.; Hou, Y.; Lam, A.Y.; Li, V.O. Intelligent fault detection scheme for microgrids with wavelet-based deep neural networks. IEEE Trans. Smart Grid 2017, 10, 1694-1703.

38. Kar, S.; Ranjan Samantaray, S. A fuzzy rule base approach for intelligent protection of microgrids. Electr. Power Compon. Syst. 2015, 43, 2082-2093. [CrossRef]

39. Kumar, D.S.; Srinivasan, D.; Reindl, T. A fast and scalable protection scheme for distribution networks with distributed generation. IEEE Trans. Power Deliv. 2015, 31, 67-75. [CrossRef] 
40. Ishchenko, D.; Oudalov, A.; Stoupis, J. Protection coordination in active distribution grids with IEC 61850. In Proceedings of the PES T\&D 2012, Orlando, FL, USA, 7-10 May 2012; pp. 1-6.

41. Deng, W.; Pei, W.; Shen, Z.; Zhao, Z.; Qu, H. Adaptive micro-grid operation based on IEC 61850. Energies 2015, 8, 4455-4475. [CrossRef]

42. Sharaf, H.M.; Zeineldin, H.H.; El-Saadany, E. Protection coordination for microgrids with grid-connected and islanded capabilities using communication assisted dual setting directional overcurrent relays. IEEE Trans. Smart Grid 2016, 9, 143-151. [CrossRef]

43. Najy, W.K.; Zeineldin, H.H.; Woon, W.L. Optimal protection coordination for microgrids with grid-connected and islanded capability. IEEE Trans. Ind. Electron. 2012, 60, 1668-1677. [CrossRef]

44. Mousavi Motlagh, S.H.; Mazlumi, K. Optimal overcurrent relay coordination using optimized objective function. Available online: http://dx.doi.org/10.1155/2014/869617 (accessed on 30 April 2020).

45. Beheshtaein, S.; Savaghebi, M.; Vasquez, J.C.; Guerrero, J.M. Protection of AC and DC microgrids: Challenges, solutions and future trends. In Proceedings of the IECON 2015-41st Annual Conference of the IEEE Industrial Electronics Society, Yokohama, Japan, 9-12 November 2015; pp. 005253-005260.

46. Mirsaeidi, S.; Dong, X.; Shi, S.; Wang, B. AC and DC Microgrids: A Review on Protection Issues and Approaches. J. Electr. Eng. Technol. 2017, 12, 2089-2098.

47. Javed, W.; Chen, D.; Farrag, M.E.; Xu, Y. System configuration, fault detection, location, isolation and restoration: A review on LVDC microgrid protections. Energies 2019, 12, 1001. [CrossRef]

48. Beheshtaein, S.; Cuzner, R.M.; Forouzesh, M.; Savaghebi, M.; Guerrero, J.M. DC microgrid protection: A comprehensive review. IEEE J. Emerg. Sel. Top. Power Electron. 2019. [CrossRef]

49. Mirsaeidi, S.; Dong, X.; Shi, S.; Tzelepis, D. Challenges, advances and future directions in protection of hybrid AC/DC microgrids. IET Renew. Power Gener. 2017, 11, 1495-1502. [CrossRef]

50. Mirsaeidi, S.; Dong, X.; Said, D.M. Towards hybrid AC/DC microgrids: Critical analysis and classification of protection strategies. Renew. Sustain. Energy Rev. 2018, 90, 97-103. [CrossRef]

51. Sarangi, S.; Sahu, B.K.; Rout, P.K. Distributed generation hybrid AC/DC microgrid protection: A critical review on issues, strategies, and future directions. Int. J. Energy Res. 2020, 44, 3347-3364. [CrossRef]

52. Barra, P.; Coury, D.; Fernandes, R. A survey on adaptive protection of microgrids and distribution systems with distributed generators. Renew. Sustain. Energy Rev. 2020, 118, 109524. [CrossRef]

53. Brearley, B.J.; Prabu, R.R. A review on issues and approaches for microgrid protection. Renew. Sustain. Energy Rev. 2017, 67, 988-997. [CrossRef]

54. Mirsaeidi, S.; Said, D.M.; Mustafa, M.W.; Habibuddin, M.H.; Ghaffari, K. An analytical literature review of the available techniques for the protection of micro-grids. Int. J. Electr. Power Energy Syst. 2014, 58, 300-306. [CrossRef]

55. Hooshyar, A.; Iravani, R. Microgrid protection. Proc. IEEE 2017, 105, 1332-1353. [CrossRef]

56. Manditereza, P.T.; Bansal, R. Renewable distributed generation: The hidden challenges-A review from the protection perspective. Renew. Sustain. Energy Rev. 2016, 58, 1457-1465. [CrossRef]

57. Habib, H.F.; Lashway, C.R.; Mohammed, O.A. A review of communication failure impacts on adaptive microgrid protection schemes and the use of energy storage as a contingency. IEEE Trans. Ind. Appl. 2017, 54, 1194-1207. [CrossRef]

58. Hosseini, S.A.; Abyaneh, H.A.; Sadeghi, S.H.H.; Razavi, F.; Nasiri, A. An overview of microgrid protection methods and the factors involved. Renew. Sustain. Energy Rev. 2016, 64, 174-186. [CrossRef]

59. Memon, A.A.; Kauhaniemi, K. A critical review of AC Microgrid protection issues and available solutions. Electr. Power Syst. Res. 2015, 129, 23-31. [CrossRef]

60. Gopalan, S.A.; Sreeram, V.; Iu, H.H. A review of coordination strategies and protection schemes for microgrids. Renew. Sustain. Energy Rev. 2014, 32, 222-228. [CrossRef]

61. Haron, A.R.; Mohamed, A.; Shareef, H. A review on protection schemes and coordination techniques in microgrid system. J. Appl. Sci. 2012, 12, 101-112. [CrossRef]

62. Almutairy, I. A review of coordination strategies and techniques for overcoming challenges to microgrid protection. In Proceedings of the 2016 Saudi Arabia Smart Grid (SASG), Jeddah, Saudi Arabia, 6-8 December 2016; pp. 1-4.

63. Basak, P.; Chowdhury, S.; nee Dey, S.H.; Chowdhury, S. A literature review on integration of distributed energy resources in the perspective of control, protection and stability of microgrid. Renew. Sustain. Energy Rev. 2012, 16, 5545-5556. [CrossRef] 
64. Keller, J.; Kroposki, B. Understanding Fault Characteristics of Inverter-Based Distributed Energy Resources; NREL: Golden CO, USA, 2010.

65. Haj-ahmed, M.A.; Illindala, M.S. The influence of inverter-based DGs and their controllers on distribution network protection. IEEE Trans. Ind. Appl. 2014, 50, 2928-2937. [CrossRef]

66. Dai, X.; Gao, Z. From model, signal to knowledge: A data-driven perspective of fault detection and diagnosis. IEEE Trans. Ind. Inform. 2013, 9, 2226-2238. [CrossRef]

67. Pillay, P.; Bhattacharjee, A. Application of wavelets to model short-term power system disturbances. IEEE Trans. Power Syst. 1996, 11, 2031-2037. [CrossRef]

68. Chaitanya, B.K.; Soni, A.K.; Yadav, A. Communication assisted fuzzy based adaptive protective relaying scheme for microgrid. J. Power Technol. 2018, 98, 57-69.

69. Kar, S.; Samantaray, S.R. Time-frequency transform-based differential scheme for microgrid protection. IET Gener. Transm. Distrib. 2014, 8, 310-320. [CrossRef]

70. Thattai, K.; Sahoo, A.; Ravishankar, J. On-line and off-line fault detection techniques for inverter based islanded microgrid. In Proceedings of the 2018 IEEE 12th International Conference on Compatibility, Power Electronics and Power Engineering (CPE-POWERENG 2018), Doha, Qatar, 10-12 April 2018; pp. 1-6.

71. Stanisavljević, A.M.; Katić, V.A.; Dumnić, B.P.; Popadić, B.P. A Comprehensive Overview of Digital Signal Processing Methods for Voltage Disturbance Detection and Analysis in Modern Distribution Grids with Distributed Generation. Acta Polytech. 2019, 16, 125-149.

72. Saleh, S.A.; Ahshan, R.; Abu-Khaizaran, M.S.; Alsayid, B.; Rahman, M. Implementing and Testing $d-q$ WPT-Based Digital Protection for Microgrid Systems. IEEE Trans. Ind. Appl. 2013, 50, 2173-2185. [CrossRef]

73. Saleh, S. Signature-coordinated digital multirelay protection for microgrid systems. IEEE Trans. Power Electron. 2013, 29, 4614-4623. [CrossRef]

74. Coifman, R.R.; Wickerhauser, M.V. Entropy-based algorithms for best basis selection. IEEE Trans. Inf. Theory 1992, 38, 713-718. [CrossRef]

75. Yang, H.; Liao, C. A de-noising scheme for enhancing wavelet-based power quality monitoring system. IEEE Trans. Power Deliv. 2001, 16, 353-360. [CrossRef]

76. Abdelgayed, T.S.; Morsi, W.G.; Sidhu, T.S. A new approach for fault classification in microgrids using optimal wavelet functions matching pursuit. IEEE Trans. Smart Grid 2017, 9, 4838-4846. [CrossRef]

77. Netsanet, S.; Zhang, J.; Zheng, D. Bagged Decision Trees Based Scheme of Microgrid Protection Using Windowed Fast Fourier and Wavelet Transforms. Electronics 2018, 7, 61. [CrossRef]

78. Dehghani, M.; Khooban, M.H.; Niknam, T. Fast fault detection and classification based on a combination of wavelet singular entropy theory and fuzzy logic in distribution lines in the presence of distributed generations. Int. J. Electr. Power Energy Syst. 2016, 78, 455-462. [CrossRef]

79. Stockwell, R.G.; Mansinha, L.; Lowe, R. Localization of the complex spectrum: The S transform. IEEE Trans. Signal Process. 1996, 44, 998-1001. [CrossRef]

80. Gururani, A.; Mohanty, S.R.; Mohanta, J.C. Microgrid protection using Hilbert-Huang transform based-differential scheme. IET Gener. Transm. Distrib. 2016, 10, 3707-3716. [CrossRef]

81. Wang, Y. The Tutorial: S Transform; Graduate Institute of Communication Engineering, National Taiwan University: Taipei, Taiwan, 2010.

82. Huang, N.E.; Shen, Z.; Long, S.R.; Wu, M.C.; Shih, H.H.; Zheng, Q.; Yen, N.; Tung, C.C.; Liu, H.H. The empirical mode decomposition and the Hilbert spectrum for nonlinear and non-stationary time series analysis. Proc. R. Soc. Lond. Ser. A Math. Phys. Eng. Sci. 1998, 454, 903-995. [CrossRef]

83. Mishra, M.; Rout, P.K. Detection and classification of micro-grid faults based on HHT and machine learning techniques. IET Gener. Transm. Distrib. 2017, 12, 388-397. [CrossRef]

84. Sadeghkhani, I.; Golshan, M.E.H.; Guerrero, J.M.; Mehrizi-Sani, A. A current limiting strategy to improve fault ride-through of inverter interfaced autonomous microgrids. IEEE Trans. Smart Grid 2016, 8, 2138-2148. [CrossRef]

85. Escudero, R.; Noel, J.; Elizondo, J.; Kirtley, J. Microgrid fault detection based on wavelet transformation and Park's vector approach. Electr. Power Syst. Res. 2017, 152, 401-410. [CrossRef]

86. Eslami, R.; Sadeghi, S.H.H.; Askarian-Abyaneh, H.; Nasiri, A. A novel method for fault detection in future renewable electric energy delivery and management microgrids, considering uncertainties in network topology. Electr. Power Compon. Syst. 2017, 45, 1118-1129. [CrossRef] 
87. Wu, Q.; Lu, Z.; Ji, T. Protective Relaying of Power Systems Using Mathematical Morphology; Springer Science \& Business Media: London, UK, 2009.

88. Mishra, M.; Panigrahi, R.R.; Rout, P.K. A combined mathematical morphology and extreme learning machine techniques based approach to micro-grid protection. Ain Shams Eng. J. 2019, 10, 307-318. [CrossRef]

89. Gush, T.; Bukhari, S.B.A.; Haider, R.; Admasie, S.; Oh, Y.; Cho, G.; Kim, C. Fault detection and location in a microgrid using mathematical morphology and recursive least square methods. Int. J. Electr. Power Energy Syst. 2018, 102, 324-331. [CrossRef]

90. Li, X.; Dyśko, A.; Burt, G.M. Traveling wave-based protection scheme for inverter-dominated microgrid using mathematical morphology. IEEE Trans. Smart Grid 2014, 5, 2211-2218. [CrossRef]

91. Santos, W.; Lopes, F.; Brito, N.; Souza, B. High-impedance fault identification on distribution networks. IEEE Trans. Power Deliv. 2016, 32, 23-32. [CrossRef]

92. Bukhari, S.B.A.; Haider, R.; Zaman, M.S.U.; Oh, Y.; Cho, G.; Kim, C. An interval type-2 fuzzy logic based strategy for microgrid protection. Int. J. Electr. Power Energy Syst. 2018, 98, 209-218. [CrossRef]

93. Wang, H.; Keerthipala, W. Fuzzy-neuro approach to fault classification for transmission line protection. IEEE Trans. Power Deliv. 1998, 13, 1093-1104. [CrossRef]

94. Hong, Y.; Wei, Y.; Chang, Y.; Lee, Y.; Liu, P. Fault detection and location by static switches in microgrids using wavelet transform and adaptive network-based fuzzy inference system. Energies 2014, 7, 2658-2675. [CrossRef]

95. Wang, S.; Chen, H. A novel deep learning method for the classification of power quality disturbances using deep convolutional neural network. Appl. Energy 2019, 235, 1126-1140. [CrossRef]

96. Baghaee, H.R.; Mlakić, D.; Nikolovski, S.; Dragičević, T. Support Vector Machine-based Islanding and Grid Fault Detection in Active Distribution Networks. IEEE J. Emerg. Sel. Top. Power Electron. 2019, 1-19. [CrossRef]

97. Samantaray, S. Decision tree-based fault zone identification and fault classification in flexible AC transmissions-based transmission line. IET Gener. Transm. Distrib. 2009, 3, 425-436. [CrossRef]

98. Ding, S.X. Model-Based Fault Diagnosis Techniques: Design Schemes, Algorithms, and Tools; Springer Science \& Business Media: London, UK, 2008.

99. Al Hassan, H.A.; Reiman, A.; Reed, G.F.; Mao, Z.; Grainger, B.M. Model-based fault detection of inverter-based microgrids and a mathematical framework to analyze and avoid nuisance tripping and blinding scenarios. Energies 2018, 11, 2152. [CrossRef]

100. Hosseinzadeh, M.; Rajaei Salmasi, F. Analysis and detection of a wind system failure in a micro-grid. J. Renew. Sustain. Energy 2016, 8, 043302. [CrossRef]

101. Poon, J.; Jain, P.; Konstantakopoulos, I.C.; Spanos, C.; Panda, S.K.; Sanders, S.R. Model-based fault detection and identification for switching power converters. IEEE Trans. Power Electron. 2016, 32, 1419-1430. [CrossRef]

102. He, H.; Liu, Z.; Hua, Y. Adaptive extended kalman filter based fault detection and isolation for a lithium-ion battery pack. Energy Procedia 2015, 75, 1950-1955. [CrossRef]

103. Hwas, A.; Katebi, R. Model-based fault detection and isolation for wind turbine. In Proceedings of the 2012 UKACC International Conference on Control, Cardiff, UK, 3-5 September 2012; pp. 876-881.

104. Cho, S.; Gao, Z.; Moan, T. Model-based fault detection, fault isolation and fault-tolerant control of a blade pitch system in floating wind turbines. Renew. Energy 2018, 120, 306-321. [CrossRef]

105. Bansal, Y.; Sodhi, R. Microgrid fault detection methods: Reviews, issues and future trends. In Proceedings of the 2018 IEEE Innovative Smart Grid Technologies-Asia (ISGT Asia), Singapore, 22-25 May 2018; pp. 401-406.

106. Hare, J.; Shi, X.; Gupta, S.; Bazzi, A. Fault diagnostics in smart micro-grids: A survey. Renew. Sustain. Energy Rev. 2016, 60, 1114-1124. [CrossRef]

107. Saha, M.M.; Izykowski, J.J.; Rosolowski, E. Fault Location on Power Networks; Springer Science \& Business Media: London, UK, 2009.

108. Majidi, M.; Etezadi-Amoli, M. A new fault location technique in smart distribution networks using synchronized/nonsynchronized measurements. IEEE Trans. Power Deliv. 2017, 33, 1358-1368. [CrossRef]

109. Farhangi, H. IEEE guide for determining fault location on ac transmission and distribution lines. IEEE Stand. Assoc. 2014, 1-76.

110. Hamidi, R.J.; Livani, H. Traveling-wave-based fault-location algorithm for hybrid multiterminal circuits. IEEE Trans. Power Deliv. 2016, 32, 135-144. [CrossRef] 
111. Ekici, S. Support Vector Machines for classification and locating faults on transmission lines. Appl. Soft Comput. 2012, 12, 1650-1658. [CrossRef]

112. Mirzaei, M.; Vahidi, B.; Hosseinian, S.H. Fault location on a series-compensated three-terminal transmission line using deep neural networks. IET Sci. Meas. Technol. 2018, 12, 746-754. [CrossRef]

113. Salim, R.; Resener, M.; Filomena, A.; De Oliveira, K.R.C.; Bretas, A.S. Extended fault-location formulation for power distribution systems. IEEE Trans. Power Deliv. 2009, 24, 508-516. [CrossRef]

114. Brahma, S.M. Fault location in power distribution system with penetration of distributed generation. IEEE Trans. Power Deliv. 2011, 26, 1545-1553. [CrossRef]

115. Beheshtaein, S.; Cuzner, R.; Savaghebi, M.; Golestan, S.; Guerrero, J.M. Fault location in microgrids: A communication-based high-frequency impedance approach. IET Gener. Transm. Distrib. 2018, 13, 1229-1237. [CrossRef]

116. Džafić, I.; Jabr, R.A.; Henselmeyer, S.; Đonlagić, T. Fault location in distribution networks through graph marking. IEEE Trans. Smart Grid 2016, 9, 1345-1353. [CrossRef]

117. Wang, Y.; Huang, Y.; Zeng, X.; Wei, G.; Zhou, J.; Fang, T.; Chen, H. Faulty feeder detection of single phase-earth fault using grey relation degree in resonant grounding system. IEEE Trans. Power Deliv. 2016, 32, 55-61. [CrossRef]

118. Duan, J.; Zhang, K.; Cheng, L. A novel method of fault location for single-phase microgrids. IEEE Trans. Smart Grid 2015, 7, 915-925. [CrossRef]

119. Pradhan, A.; Routray, A.; Gudipalli, S.M. Fault direction estimation in radial distribution system using phase change in sequence current. IEEE Trans. Power Deliv. 2007, 22, 2065-2071. [CrossRef]

120. Lei, L.; Wang, C.; Gao, J.; Zhao, J.; Wang, X. A Protection Method Based on Feature Cosine and Differential Scheme for Microgrid. Math. Probl. Eng. Available online: https://doi.org/10.1155/2019/7248072 (accessed on 30 April 2020). [CrossRef]

121. Babayomi, O.O.; Oluseyi, P.O. Intelligent fault diagnosis in a power distribution network. Adv. Electr. Eng. Available online: https://doi.org/10.1155/2016/8651630 (accessed on 30 April 2020). [CrossRef]

122. Borghetti, A.; Bosetti, M.; Nucci, C.; Paolone, M.; Abur, A. Integrated use of time-frequency wavelet decompositions for fault location in distribution networks: Theory and experimental validation. IEEE Trans. Power Deliv. 2010, 25, 3139-3146. [CrossRef]

123. Habib, H.F.; Youssef, T.; Cintuglu, M.H.; Mohammed, O.A. Multi-agent-based technique for fault location, isolation, and service restoration. IEEE Trans. Ind. Appl. 2017, 53, 1841-1851. [CrossRef]

124. Farughian, A.; Kumpulainen, L.; Kauhaniemi, K. Earth Fault Location Using Negative Sequence Currents. Energies 2019, 12, 3759. [CrossRef]

125. Suryanarayana, G.; Rao, G.K.; Sarangi, S.; Raja, P. Directional relaying using parameter estimation approach. Int. J. Electr. Power Energy Syst. 2019, 107, 597-604. [CrossRef]

126. Jones, D.; Kumm, J.J. Future distribution feeder protection using directional overcurrent elements. IEEE Trans. Ind. Appl. 2013, 50, 1385-1390. [CrossRef]

127. Muda, H.; Jena, P. Superimposed adaptive sequence current based microgrid protection: A new technique. IEEE Trans. Power Deliv. 2016, 32, 757-767. [CrossRef]

128. Akter, S.; Das, P.; Roy, B.S.; Abdelaziz, A.Y. Positive-Sequence Component Based Directional Relaying Algorithm for Single-Pole Tripping. Arab. J. Sci. Eng. 2019, 1-15. [CrossRef]

129. Jalilian, A.; Hagh, M.T.; Hashemi, S. An innovative directional relaying scheme based on postfault current. IEEE Trans. Power Deliv. 2014, 29, 2640-2647. [CrossRef]

130. Hooshyar, A.; Iravani, R. A new directional element for microgrid protection. IEEE Trans. Smart Grid 2017, 9, 6862-6876. [CrossRef]

131. Samet, H.; Ghanbari, T.; Jarrahi, M.A.; Ashtiani, H.J. Efficient Current-Based Directional Relay Algorithm. IEEE Syst. J. 2018, 13, 1262-1272. [CrossRef]

132. Van Tu, D.; Chaitusaney, S.; Yokoyama, A. Fault current calculation in distribution systems with inverter-based distributed generations. IEEJ Trans. Electr. Electron. Eng. 2013, 8, 470-477. [CrossRef]

133. Karady, G.G.; Mandava, P. Pilot directional protection using negative sequence directional element. In Proceedings of the 2014 Clemson University Power Systems Conference, Clemson, SC, USA, 11-14 March 2014; pp. 1-5.

134. Ashtiani, H.J.; Samet, H.; Ghanbari, T. Simple current-based algorithm for directional relays. IET Gener. Transm. Distrib. 2017, 11, 4227-4237. [CrossRef] 
135. Hosseini, H.S.; Koochaki, A.; Hosseinian, S.H. A Novel Scheme for Current Only Directional Overcurrent Protection Based on Post-Fault Current Phasor Estimation. J. Electr. Eng. Technol. 2019, 1-11. [CrossRef]

136. Jena, P.; Pradhan, A.K. A positive-sequence directional relaying algorithm for series-compensated line. IEEE Trans. Power Deliv. 2010, 25, 2288-2298. [CrossRef]

137. Gu, B.; Tan, J.; Wei, H. High speed directional relaying algorithm based on the fundamental frequency positive sequence superimposed components. IET Gener. Transm. Distrib. 2014, 8, 1211-1220. [CrossRef]

138. Lin, H.; Guerrero, J.M.; Vásquez, J.C.; Liu, C. Adaptive distance protection for microgrids. In Proceedings of the 41st Annual Conference of the IEEE Industrial Electronics Society (IECON 2015), Yokohama, Japan, 9-12 November 2015; pp. 000725-000730.

139. Horowitz, S.H.; Phadke, A.G. Power System Relaying; John Wiley \& Sons Ltd.: West Sussex, UK, 2008; Vol. 22, ISBN 9781118662007.

140. Blackburn, J.L.; Domin, T.J. Protective Relaying: Principles and Applications; CRC Press: Boca Raton, FL, USA, 2014.

141. Huang, W.; Nengling, T.; Zheng, X.; Fan, C.; Yang, X.; Kirby, B.J. An impedance protection scheme for feeders of active distribution networks. IEEE Trans. Power Deliv. 2014, 29, 1591-1602. [CrossRef]

142. Elkhatib, M.; Ellis, A.; Biswal, M.; Brahma, S.; Ranade, S. Protection of Renewable-Dominated Microgrids: Challenges and Potential Solutions; Sandia National Laboratories: Albuquerque, NM, USA, 2016.

143. Nasir, M.; Bhatti, A.A. A Micro Computer-Based Methodology for Distance Protection on Long UHV Transmission Lines Using Symmetrical Components. In Proceedings of the 2012 Asia-Pacific Power and Energy Engineering Conference, Shanghai, China, 27-29 March 2012; pp. 1-6.

144. Dewadasa, M.; Ghosh, A.; Ledwich, G. Protection of microgrids using differential relays. In Proceedings of the AUPEC 2011, Brisbane, QLD, Australia, 25-28 September 2011; pp. 1-6.

145. Han, B.; Li, H.; Wang, G.; Zeng, D.; Liang, Y. A Virtual Multi-Terminal Current Differential Protection Scheme for Distribution Networks with Inverter-Interfaced Distributed Generators. IEEE Trans. Smart Grid 2018, 9, 5418-5431. [CrossRef]

146. Etemadi, A.H.; Iravani, R. Overcurrent and overload protection of directly voltage-controlled distributed resources in a microgrid. IEEE Trans. Ind. Electron. 2012, 60, 5629-5638. [CrossRef]

147. Oureilidis, K.O.; Demoulias, C.S. A fault clearing method in converter-dominated microgrids with conventional protection means. IEEE Trans. Power Electron. 2015, 31, 4628-4640. [CrossRef]

148. Costa, F.B.; Monti, A.; Paiva, S.C. Overcurrent protection in distribution systems with distributed generation based on the real-time boundary wavelet transform. IEEE Trans. Power Deliv. 2015, 32, 462-473. [CrossRef]

149. Laaksonen, H.; Hovila, P. Method for high-impedance fault detection. CIRED-Open Access Proc. J. 2017, 2017, 1295-1299. [CrossRef]

150. Zhao, W.; Alexandre, O.; Bin, S.; Yao, C. Research on close-loop simulation for centralized coordination of protection settings. In Proceedings of the 2012 China International Conference on Electricity Distribution, Shanghai, China, 10-14 September 2012; pp. 1-6.

151. Mohamed, E.A.; Magdy, G.; Shabib, G.; Elbaset, A.A.; Mitani, Y. Digital coordination strategy of protection and frequency stability for an islanded microgrid. IET Gener. Transm. Distrib. 2018, 12, 3637-3646. [CrossRef]

152. Jain, R.; Lubkeman, D.L.; Lukic, S.M. Dynamic Adaptive Protection for Distribution Systems in Grid-Connected and Islanded Modes. IEEE Trans. Power Deliv. 2018, 34, 281-289. [CrossRef]

153. Sharma, A.; Panigrahi, B.K. Phase fault protection scheme for reliable operation of microgrids. IEEE Trans. Ind. Appl. 2017, 54, 2646-2655. [CrossRef]

154. Mahat, P.; Chen, Z.; Bak-Jensen, B.; Bak, C.L. A simple adaptive overcurrent protection of distribution systems with distributed generation. IEEE Trans. Smart Grid 2011, 2, 428-437. [CrossRef]

155. Bukhari, S.; Haider, R.; Zaman, M.; Oh, Y.; Cho, G.; Kim, M.; Kim, J.; Kim, C. Adaptive Centralized Protection Scheme for Microgrids Based on Positive Sequence Complex Power. In Proceedings of the International Conference on Power Systems Transients 2017, Seoul, Korea, 26-29 June 2017.

156. Lin, H.; Guerrero, J.M.; Jia, C.; Tan, Z.; Vasquez, J.C.; Liu, C. Adaptive overcurrent protection for microgrids in extensive distribution systems. In Proceedings of the 42nd Annual Conference of the IEEE Industrial Electronics Society (IECON 2016), Florence, Italy, 23-26 October 2016; pp. 4042-4047.

157. Kumar, D.S.; Srinivasan, D.; Sharma, A.; Reindl, T. Adaptive directional overcurrent relaying scheme for meshed distribution networks. IET Gener. Transm. Distrib. 2018, 12, 3212-3220. [CrossRef] 
158. Cintuglu, M.H.; Ma, T.; Mohammed, O.A. Protection of autonomous microgrids using agent-based distributed communication. IEEE Trans. Power Deliv. 2016, 32, 351-360. [CrossRef]

159. Eissa, M.; Awadalla, M.H. Centralized protection scheme for smart grid integrated with multiple renewable resources using Internet of Energy. Glob. Transit. 2019, 1, 50-60. [CrossRef]

160. Nikolaidis, V.C.; Papanikolaou, E.; Safigianni, A.S. A communication-assisted overcurrent protection scheme for radial distribution systems with distributed generation. IEEE Trans. Smart Grid 2015, 7, 114-123. [CrossRef]

161. Zhou, X.; Zhou, L.; Chen, Y.; Guerrero, J.M.; Luo, A.; Wu, W.; Yang, L. A microgrid cluster structure and its autonomous coordination control strategy. Int. J. Electr. Power Energy Syst. 2018, 100, 69-80. [CrossRef]

162. Zhang, F.; Mu, L. New protection scheme for internal fault of multi-microgrid. Prot. Control Mod. Power Syst. 2019, 4, 14. [CrossRef]

163. Khayat, Y.; Shafiee, Q.; Heydari, R.; Naderi, M.; Dragicevic, T.; Simpson-Porco, J.W.; Dorfler, F.; Fathi, M.; Blaabjerg, F.; Guerrero, J.M. On the Secondary Control Architectures of AC Microgrids: An Overview. IEEE Trans. Power Electron. 2019, 35, 6482-6500. [CrossRef]

164. Samet, H.; Azhdari, E.; Ghanbari, T. Comprehensive study on different possible operations of multiple grid connected microgrids. IEEE Trans. Smart Grid 2016, 9, 1434-1441. [CrossRef]

165. Bazmohammadi, N.; Tahsiri, A.; Anvari-Moghaddam, A.; Guerrero, J.M. Stochastic Predictive Control of Multi-Microgrid Systems. IEEE Trans. Ind. Appl. 2019, 55, 5311-5319. [CrossRef]

166. Atteya, A.I.; El Zonkoly, A.M.; Ashour, H.A. Adaptive protection scheme for optimally coordinated relay setting using modified PSO algorithm. J. Power Technol. 2017, 97, 463-469.

167. Dehghanpour, E.; Karegar, H.K.; Kheirollahi, R.; Soleymani, T. Optimal coordination of directional overcurrent relays in microgrids by using cuckoo-linear optimization algorithm and fault current limiter. IEEE Trans. Smart Grid 2016, 9, 1365-1375. [CrossRef]

168. Shih, M.Y.; Salazar, C.A.C.; Enríquez, A.C. Adaptive directional overcurrent relay coordination using ant colony optimisation. IET Gener. Transm. Distrib. 2015, 9, 2040-2049. [CrossRef]

169. Yazdanpanahi, H.; Li, Y.W.; Xu, W. A new control strategy to mitigate the impact of inverter-based DGs on protection system. IEEE Trans. Smart grid 2012, 3, 1427-1436. [CrossRef]

170. Ustun, T.S.; Ozansoy, C.; Ustun, A. Fault current coefficient and time delay assignment for microgrid protection system with central protection unit. IEEE Trans. Power Syst. 2012, 28, 598-606. [CrossRef]

171. Alam, M.N. Adaptive protection coordination scheme using numerical directional overcurrent relays. IEEE Trans. Ind. Inform. 2018, 15, 64-73. [CrossRef]

172. El-Naily, N.; Saad, S.M.; Hussein, T.; Mohamed, F.A. A novel constraint and non-standard characteristics for optimal over-current relays coordination to enhance microgrid protection scheme. IET Gener. Transm. Distrib. 2019, 13, 780-793. [CrossRef]

173. Zamani, M.A.; Sidhu, T.S.; Yazdani, A. A protection strategy and microprocessor-based relay for low-voltage microgrids. IEEE Trans. Power Deliv. 2011, 26, 1873-1883. [CrossRef]

174. Fani, B.; Bisheh, H.; Sadeghkhani, I. Protection coordination scheme for distribution networks with high penetration of photovoltaic generators. IET Gener. Transm. Distrib. 2017, 12, 1802-1814. [CrossRef]

175. Dahej, A.E.; Esmaeili, S.; Hojabri, H. Co-optimization of Protection Coordination and Power Quality in Microgrids Using Unidirectional Fault Current Limiters. IEEE Trans. Smart Grid 2017, 9, 5080-5091. [CrossRef]

176. He, H.; Chen, L.; Yin, T.; Cao, Z.; Yang, J.; Tu, X.; Ren, L. Application of a SFCL for fault ride-through capability enhancement of DG in a microgrid system and relay protection coordination. IEEE Trans. Appl. Supercond 2016, 26, 1-8. [CrossRef]

177. Saberi, H.; Amraee, T. Coordination of directional over-current relays in active distribution networks using generalised benders decomposition. IET Gener. Transm. Distrib. 2017, 11, 4078-4086. [CrossRef]

178. Albasri, F.A.; Alroomi, A.R.; Talaq, J.H. Optimal coordination of directional overcurrent relays using biogeography-based optimization algorithms. IEEE Trans. Power Deliv. 2015, 30, 1810-1820. [CrossRef]

179. Huchel, Ł.; Zeineldin, H.H. Planning the coordination of directional overcurrent relays for distribution systems considering DG. IEEE Trans. Smart Grid 2015, 7, 1642-1649. [CrossRef]

180. Alkaran, D.S.; Vatani, M.; Sanjari, M.; Gharehpetian, G.B.; Naderi, M. Optimal overcurrent relay coordination in interconnected networks by using fuzzy-based GA method. IEEE Trans. Smart Grid 2016, 9, 3091-3101. [CrossRef] 
181. Saleh, K.A.; Zeineldin, H.H.; El-Saadany, E.F. Optimal Protection Coordination for Microgrids Considering N-1 Contingency. IEEE Trans. Ind. Inform. 2017, 13, 2270-2278. [CrossRef]

182. Ojaghi, M.; Mohammadi, V. Use of clustering to reduce the number of different setting groups for adaptive coordination of overcurrent relays. IEEE Trans. Power Deliv. 2017, 33, 1204-1212. [CrossRef]

183. Aghdam, T.S.; Karegar, H.K.; Zeineldin, H.H. Variable tripping time differential protection for microgrids considering DG Stability. IEEE Trans. Smart Grid 2018, 10, 2407-2415. [CrossRef]

184. Tsimtsios, A.M.; Nikolaidis, V.C. Towards Plug-and-Play Protection for Meshed Distribution Systems with DG. IEEE Trans. Smart Grid 2020, 11, 1980-1995. [CrossRef]

C 2020 by the authors. Licensee MDPI, Basel, Switzerland. This article is an open access article distributed under the terms and conditions of the Creative Commons Attribution (CC BY) license (http://creativecommons.org/licenses/by/4.0/). 